ENSAIO ECONÔMICO NO 111

THE BAYESIAN FOUNDATIONS OF SOLUTION CONCEPTS

OF GAMES

Sérgio Ribeiro da Costa Werlang

Tommy Chin - Chiu Tan

1987

anpas Obra pubsicadacóna

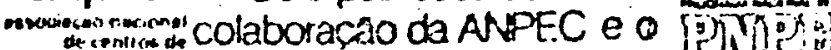

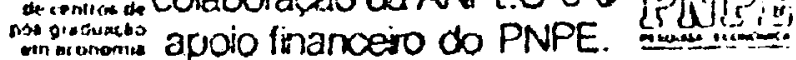




\section{The Bayesian Foundations of Solution Concepts of Games}

Tommy Chin-Chiu Tan

Graduate School of Business

University of Chicago

and

Sérgio Ribeiro da Costa Werlang

Princetọn University \& IMPA and EPGE-FGV

\section{Abstract}

We transform a non co-operative game into a Bayesian decision problem for each player where the uncertainty faced by a player is the strategy choices of the other players, the priors of other players on the choice of other players, the priors over priors and so on. We provide a complete characterization between the extent of knowledge about the rationality of piayers and their ability to successfully eliminate strategies which are not best responses. This paper therefore provides the informational foundations of iteratively undominated strategies and rationalizable strategic behavior (Bernheim (1984) and Pearce (1984)). Moreover, sufficient conditions are also found for Nash equilibrium behavior. We also provide Aumann's (1985) results on correlated equilibria.

* This paper is a substantially expanded and revised version of "The Bayesian Foundations of Rationalizable Strategic Behavior and Nash Equilibrium Behavior." We wish to acknowledge the tremendous help and useful discussions we have had with Roger Myerson who first brought our attention to the Armbruster and Böge (1979) paper. Discussion with David Hirshleifer, José Alexandre Scheinkman and Hugo Sonnensche in have also helped to clarify our ideas.

* This author thanks CNPq and IMPA/CNPq for financial support. 


\section{INTRODUCTION}

In recent years, game theorists have witnessed a proliferation of solution concepts for non-cooperative games. The main solution concept -- which some have argued to be a necessary condition for any solution concept -- is still the Nash equilibrium. However, it has long been noticed that the set of Nash equilibria for a game may be very large and some of these equilibria may violate the collective "intuition" of economists or game theorists. Thus, the refinements of the Nash equilibrium concept aim to narrow the set of equilibria by weeding out points which are "counter-intuitive."

That there is less unanimity about this weeding process can be deduced from the diverse proposals: subgame perfection and perfection of Selten (1965 and 1975); properness of Myerson (1978); sequential equilibrium of Kreps and Wilson (1982); stability of Kohlberg and Mertens (1982); intuitive criterion of Kreps (1984); neoligism proofness of Farrel (1984); perfect sequential equilibrium of Grossman and Perry (1984); extended intuitive criterion of Cho (1985); Justifiability of McClennan (1985); divinity of Banks and Sobel (1985). We apologize for missing citations and concepts.

A minority view of solution concepts reject the necessity of the Nash property and propose alternative solution concepts which are supersets of the Nash concept. These include the correlated equilibria of Aumann (1974), dominance solvability of Moulin'(1979), and rationalizability of Bernheim (1984) and Pearce (1984).

An outside observer, who may wish to apply game theory to a problem and originally confused by the multiplicity of Nash equilibria, is now bewildered by this wealth of solution concepts. A consequence of this embarassment of riches is that it falls incumbent upon game theorists to clarify several important 
issues: (i) What are the implicit assumptions we are making about the players in the game in order that we can predict their behaviour to be consistent with one equilibrium concept and not another? (ii) What is the relationship between the different concepts? (iii) In an economic problem of interest which has been modelled as a non-cooperative game, which solution concept is the most appropriate for the situation? (iv) Or is it the case that one solution concept is appropriate for all games and situations?

The purpose of this paper is not to introduce another solution concept. This paper is motivated by our own confusion with the different solution concepts. Our intention is to provide a Bayesian framework in which each solution concept may be derived from an explicit set of basic assumptions about the behaviour, information and beliefs of the players in the game. Through this framework, we hope to answer some of the questions which were raised above.

The main focus of our work is in explicating the implicit assumptions about the players in a game which would lead them to take actions consistent with a particular solution concept. We are therefore directly concerned with question (i) stated above. After setting up the general Bayesian framework, we apply it to investigate the assumptions required to generate four solution concepts: interative elimination of strictly dominated strategies, rationalizable, Nash and correlated equilibrium.

One level of the relationship between solution concepts is already well understood -- the points admitted by one solution concept may be contained in the points admitted by another solution concept. In general, every proper equilibrium is perfect, which is in turn sequential, which is subgame perfect, which is Nash and every Nash is rationalizable. Hence, the nested implications of the solution concepts in each game is well understood. Once the underlying assump:tions are made explicit, one can also see if they are nested and if not ask where 
they differ. Suppose we wish to investigate the relationship between rationalizable and Nash equilibria, say. Since we know that every Nash is rationalizable but not vice versa, once we have the assumptions underlying each concept and understand their differences, then all aspects of the relationship between the two would be known.

We feel that this method of comparing solution concepts is more satisfactory than the usual practice of comparing them in simple examples. These examples frequently have multiple Nash equilibria, some supposedly less "intuitive" than others. An advocate of one solution concept would then point out the efficacy of that concept in rejecting counterintuitive points in one example, only to be confronted by another example, constructed by an advocate of another solution concept to embarass the original concept. Frequently, what is considered "intuitive" is also a subject of debate. The use of the framework provided here shifts the debate to a systematic comparison of the foundational assumptions (or the axioms of behavior and beliefs) for each solution concept rather than their "performance" in examples.

The guiding principle is our belief that, once the set of necessary and sufficient assumptions about players corresponding to each solution concept is found, objective analysis can go no further. The remaining task involves a subjective comparison of these sets of assumptions. Just as an economic model can be judged by its underlying assumptions and sometimes adopted as a paradigm through the consensus of economists, so should the solution concepts of games. Just as an ecoomic model about a market economy may not be appropriate for a centralized economy, a solution concept which may be appropriate for a simultaneous game played by two students who encountered that gane in their class that morning, may be inappropriate for the very same game played by two illiterates, one from South-East Asia and the other from Brazil -- even though each of these 
players is rational. To facilitate these considerations, we feel that the implicit assumptions behind each solution concept must be carefully stated to allow the user to choose the set of assumptions and hence the solution set he is comfortable with.

The answer to one question seems clear to us -- that there is in no sense a universal solution concept appropriate for all games. Solution concepts which admit few points, and which are highly predictive, are generally those which have the strongest underlying assumptions. On the other hand, weaker sets of assumptions lead to solution concepts which accept more outcomes for the game and are therefore less predictive. In our framework, a person applying game theory to a particular situation must use his experience to specify the underlying assumptions on the behavior, information and beliefs of the players. The solution concept is then derived as a consequence of these assumptions.

Section 1.1 discusses axiomatic approaches to game theory, and Section 1.2 provides a preview of the results in the paper. Section 2 discusses related - literature. Section 3 provides the Bayesian framework and Section 4 begins the Bayesian foundation of solution concepts. Section 5 derives iteratively undominated strategies and rationalizable strategies from basic axioms. Section 6 provides several alternative derivations of Nash equilibrium. Section 7 provides the Aumann (1985) result on correlated equilibria as well as subjective correlated equilibrium. Section 8 presents our conclusion and a subjective discussion of our results. There are two technical Appendices.

\subsection{AXIOMATIC APPROACHES TO SOLUTION CONCEPTS}

It should be clear that we are aiming at an axiomatic approach to the solution concepts of games. The usual approach to the definition of a solution concept has been to define it mathematically for a given game. For example, the Nash equilibrium is simply defined as the fixed point of the best response 
correspondence, and a perfect equilibrium is the limit, as the perturbation disappears, of a sequence of Nash equilibria of perturbed games. These definitions have little to say about the underlying behavior, information and beliefs of the players in the normal form game which would lead them to play accordingly to a solution concept.

Some exceptions to this approach can be seen in the equilibrium concepts which are not necessarily Nash equilibria. The papers of Bernheim (1984, 1985), Pearce (1984) and Aumann (1985) are essentially axiomatic in spirit and their solution concepts are derived from underlying behavioral and informational assumptions. As a result, even though some of their arguments may not have been rigorous, they can be easily formalized in an appropriate framework, such as the one presented in this paper. The advantage, of deriving each from assumptions made in the same formal language, is that it facilitates their comparison.

The model of games presented in this paper is Bayesian in spirit. It takes a given normal form game and transforms it into a Bayesian decision problem in the sense of Savage. The basic space of uncertainty which a player faces is the strategic choice of the other players in the game. The player therefore has a prior over the strategy sets of the other players. Moreover, each player is also uncertain about the priors on strategies of the other players. Hence each player must also have priors on the priors of the other players, and so on. Thus, beginning with a game in normal form, we are led to study an infinite recursion of beliefs for the players -- a mathematical object which has been investigated by Armbruster and Böge (1979), Böge and Eisele (1979) and Mertens and Zamir $(1985)$.

In this approach, the axioms or assumptions underlying a solution concept are restrictions placed on the infinite recursion of beliefs of each player as well as on how the player behaves given a particular stream of beliefs. Hence, 
axions are assumptions on the behavior and beliefs of a Bayesian player in the normal form game. For example, an axiom which we analyze in detail is: ミach player is rational (in the sense of Savage), each player believes that every player is rational, ... rationality is common knowledge. The Bayesian framework provides an explicit formalization of this statement and we are able to derive all the implications of this particular axiom.

It should be noted that the axiomatic approach of this paper is very different from that envisaged by Kohlberg (1981). Konlberg's proposed axioms are conditions placed on the performance of a solution concept on the normal and extensive forms. For example, one of the axions he suggests is subgame replacement. In any case, Abreu and Pearce (1985) have shown that a strict subset of his proposed axioms are internally inconsistent.

As mentioned earlier, this paper applies the framework to investigate the different axioms required to generate four existing solution concepts, to highlight their relationships. We are not yet prepared to advocate our own set of axioms on the behavior and beliefs of the players (and hence a particular solution concept). We feel that this is a matter which can only be settled either by consensus or by tailoring assumptions to the situation at hand.

\subsection{PREVIEW OF RESULTS}

In addition to the introduction and development of the framework, we apply

it to four solution concepts. We discuss here the assumptions which generate the four solution concepts.

\section{-}

We first show that a Bayesian rational player of the game (one who chooses a trategy to maximize expected payoff given his prior on the strategies of the ther players) will choose an action which survives $\&$ levels of elimination of trictly dominated strategies if he believes that "everyone (believes that everyhe $)^{\ell-1}$ is rational" and if there are no other restrictions imposed on his 
beliefs. Moreover, "rationality is common knowledge" leads to his taking an action which survives all iterations of removing strictly dominated strategies.

Next, a Eayesian rational player, who in addition to believing that rationality is known up to level $\ell-1$, believes also that "players act independently" is also known up to level $\ell-1$, will take an action which survives $\ell$ iterations of eliminating non-best responses. In the limit, when both are common knowledge, he will take an action which is rationalizable in the sense of Bernheim (1984) and of Pearce (1984). We proceed to show that every action which survives all iterative eliminations of strictly dominated strategies, can be supported by a consistent stream of beliefs satisfying the common knowledge of - rationality. A similar result applies for rationalizable strategies.

Hence, a person wishing to apply a normal form game to study a given situation, and who is unwilling to assume more than "rationality is conmon knowledge" cannot use a solution concept which is stronger than iteratively undominated strategies. If in addition, he is willing to assume that "players act independently" is also common knowledge, then the appropriate solution concept is rationalizability.

We first formalize the traditional defense of Nash theory -- that if a theory (equivalently, a solution concept) is common knowledge and knowledge of a theory does not lead one to violate it, then the theory must be Nash equilibrium. This result is essentially a redefinition of a Nash equilibrium. We then relax this by not requiring a solution concept to be common knowledge, but requiring that it be among the behavior each player believes the other players are capable of. We show that, combined with rationality is comnon knowledge, the possibility of a solution concept being played, leads to Nash equilibrium behavior in a three firm Cournot oligopoly (the same game has many rationalizable strategies, even though the two firm version has a unique rationalizable strategy equal to the 
Nash strategy). However, a severe multiplicity of behavior consistent with these restrictions occurs; when there are four firms.

Next, we show that beliefs and rationality being common knowledge in a two person game results in a Nash equilibrium being played. A Nash equilibrium in mixed strategies is given a new interpretation where the mixed strategy of player $J$ becomes the Eeyasian prior of player $i$ on the strategic choice of player $j$. Beliefs being comnon knowledge when there are more than two players, however, does not lead to a Nash equilibrium. This surprising result is demonstrated in a three player game. The problem is that even though the beliefs are common knowledge, they are not common and therefore not Naṣh. (See also Section 7 on correlated equilibrium.)

The final results on Nash equilibrium provide a set of axioms on a player's priors, which, through the introspection process alone, would lead to the player playing a Nash equilibrium strategy. One set of assumptions, besides "rationality is common knowledge," requires two properties of the beliefs: conjectural consistency and exchangeability. Conjectural consistency requires that each person believes that the others may be correct about himself -- that is, if player $i$ has certain celiefs, $s_{i}^{\infty}$, then he must believe $s_{i}^{\infty}$ must be among the possible beliefs which player $k$ may have about player $i$ himself. This is another instance of the Nash equilibrium requiring that the players "know" more about each other than just "rationality is common knowledge." This is of course far weaker than requiring Nash beliefs as above.

In our framework, we require that player $i$ must have beliefs about the infinite recursion of beliefs of player $j$, as well as about the strategies of player J. Exchangeability requires that the prior of player $i$ on these two sets must be supported by the product of two subsets of each set. In other words, if player i thinks that playing strategy one while having belief one 
could possibly describe player $j$, as well as playing strategy two while having belief two, then player $i$ must believe that playing strategy one while having belief two could also describe player $j$. The restriction here is on the support of i's prior, and not on the measure itself. Of course, stochastic independence would satisfy this condition. This is less intuitive than the other axioms we examine, but still weaker than requiring a theory or the beliefs to be common knowledge. In some sense, it appears similar to the principle of insufficient reason in this context.

Finally, we derive axioms which lead to a correlated equilibrium. This is a reformulation of Aumann (1985) in our framework. The use of the infinite recursion of beliefs allows us to highlight an implicit assumption in Aumann's original formulation and indicate when it is necessary. In terms of behavioral and informational assumptions, correlated equilibrium requires the strongest hypotheses. It requires that each player's beliefs are conditional distributions from a common prior. There is also a strong sense of centralization and coordination wich is not present in the other solution concepts. It requires that not only did the players talk before the game was played, they established a common payof irrelevant randomization to coordinate their activities. Subjective correlated equilibria are also discussed and we argue that they are the same as iteratively undominated strategies given our earlier results.

\section{DISCUSSION OF RELATED LITERATURE}

The pioneering papers in the Bayesian approach are those of Harsanyi (196768), Armbruster and Böge (1979), Böge and Eisele (1979) and Mertens and Zamir (1985). This paper cannot possibly have been written without the foundational work contained in these four contributions. The spirit of this paper is closer to that of Armbruster and Böge (1979) and Böge and Eisele (1979). Those papers were concerned with solution concepts for games as well. Bernheim (1984) and 
Pearce (1984) provided the arguments on which the results for rationalizability are based.

Between the first revision of this paper (October, 1984) and the current revision, several independent articles -- some very closely related in form and spirit, others only in spirit -- have come to our attention.

Aumann (1985), which derived correlated equilibrium axiomatically and from which Section 7 of this paper was taken, uses a framework which is based on the Aumann (1976) definition of common knowledge. Informal versions of Aumann (1985) have been given since before the very first draft of this paper was written (May, 1984).

Bernheim (1985) discusses many of the issues with the four solution concepts touched upon in this paper and contains similar results. In earlier versions of this paper, the term "Axiom" was not used; only "restrictions on beliefs" were imposed. Our new boldness here, reflects Bernheim's leadership. The axioms he studies are $[R],[I]$ and $[C P]$, and although his framework does not permit a discussion of knowledge and layers of knowledge, there is a large intersection of subject matter.

Brandenberg and Dekel (1985) have also begun to apply the Bayesian framework to games. They study the relationship between correlated equilibrium, subjective correlated equilibrium and rationalizable.

Binmore (1985) contains many sentiments about the proliferation of solution concepts which have also motivated our paper. His approach, the use of finite automata and Turing machines, is drastically different from the Bayesian approach. Finite automata are genetically encoded to frown at infinite recursions.

The framework we use in the analysis of normal form games can be extended to extensive form games. Reny (1985) presents a first step in this direction and 
points out the rather disturbing fact that "rationality is common knowledge" cannot be imposed at every information set. Some information sets are reached only if that hypothesis is blatantly violated.

\section{GAMES AS BAYESIAN DECISION PROBLEMS}

In this section we will set up the Bayesian framework for analyzing the foundational issues which we are interested in. We shall be concerned with the following complete information simultaneous game:

Definition 3.1: A gane with $\mathrm{n}$ players, $I$, is a 2n-tuple $\left(A_{1}, \ldots, A_{n}, \bar{U}_{1}, \ldots, \overline{0}_{n}\right)$, where:

(i) Each $A_{i}$, the set of strategies or actions available to player $i$, is a compact metric space;

(ii) If one denotes $A=\prod_{j=1}^{n} A_{j}, \quad \bar{U}_{i}$ is a function from $A$ to $R$, which gives the payoffs to player $i$, for each of the possible combination of strategies of all players. $\bar{U}_{i}$ is assumed to be continuous for each $i$. (When $\left\{x_{i}\right\}_{i=1}^{n}$ is of interest, we let $x_{-i}=\underset{j \neq i}{I} x_{i} \cdot$ )

We assume that the structure of $r$ is well understood by all the players. (This is formalized in the axiom at the end of this section.) The remainder of this section will convert the game $\Gamma$ into a Bayesian decision problem for player i: [If $S$ is compact and metric, let $\Delta(S)$ be the set of probability measures on $S$ endowed with the Borel o-algebra. Furthermore, $\Delta(S)$, endowed with the topology of weak convergence of measures, is compact and metrizable -see Billingsley (1968) or Hildenbrand (1974).]

Definition 3.2: A Bavesian decision problem for player $i$ is given by (i) $S_{i}$ a compact metric probability space endowed with the Borel o-algebra. 
$S_{i}$ represents all the elements which are uncertain to player $i ;$ (ii) $A_{i}$, a compact set of actions available to player $i ;$ (iii) $U_{i}: A_{i} \times S_{i}+R$, his subjective utility function; and (iv) $P_{i} \varepsilon \Delta\left(S_{i}\right)$, his subjective prior on $S_{i}$.

Given a decision problem, one can derive structure above from more basic facts, as in Savage: (1954). It is important to note that $U_{i}$ and $P_{i}$ characterize player i.

Definition 3.3: Let $V_{i}: A_{i} \times \Delta\left(S_{i}\right)+R$ be the expected subjective utility for player $i$, when he takes an action $a_{i}$, and has prior $P_{i}: V_{i}\left(a_{i}, P_{i}\right)=\int_{S_{i}} U_{i}\left(a_{i}, s_{i}\right) d P_{i}\left(s_{i}\right)$ To avoid unnecessary notation, we will simply write $V\left(a_{i}, P_{i}\right)$ instead of $v_{i}\left(a_{i}, P_{i}\right)$.

Definition 3.4: Player i is Bayesian rational when, faced with a Bayesian decision problem, he chooses an action $\bar{a}_{i} \varepsilon A_{i}$ such that

$$
v\left(\bar{a}_{i}, P_{i}\right) \geq V\left(a_{i}, P_{i}\right), \quad \forall a_{i} \varepsilon \dot{A}_{i} \text {. }
$$

We are therefore searching for a reasonable specification of the universal space of uncertainty $S_{i}$, for player $i$, which contains all the elements of his uncertainty. Once this is derived, we need to specify his utility function $U_{i}$ and his prior $P_{i}$ to complete the conversion of the game in Def. 3.1 into a decision problem in Def. 3.2 .

The simultaneity of the game $\Gamma$ implies that player $i$ chooses a strategy in ignorance of the strategies chosen by the other players. Hence the basic uncertainty that player i faces is:

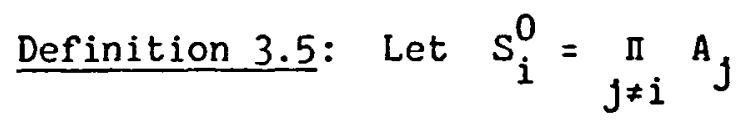

Player $i$, who is Bayesian, must have a prior on this basic uncertainty. Such a prior is a point in the set of all probability measures on $\underset{j \neq i}{\mathbb{I}} A_{j}$ : 
Definition 3.6: Let $S_{i}^{1}=\Delta\left(\underset{j \neq i}{\Pi} A_{j}\right)=\Delta\left(S_{i}^{0}\right)$

$s_{i}^{0}$ does not exhaust the uncertainty faced by player $i$. He realizes that player $j$ must have a prior on $s_{j}^{0}$ as well, and this prior or the first layer belief of player $j$-- a point in $s_{j}^{1}$-- is unknown to player $i$. Consequently, $\underset{j \neq i}{\text { II }} S_{j}^{1}$, the first layer beliefs of the other players, is also part of the uncertainty faced by player i. Thus, $i$ must have a prior in this as well and such a prior would be a point in the set of all probability measures on $\prod_{j \neq i} s_{j}^{1}$ as well as on the basic uncertainty:

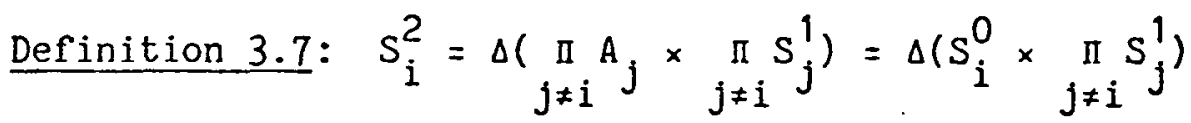

Notice that we have included $S_{i}^{0}=\underset{j \neq i}{\prod} A_{j}$, the basic uncertainty space, in the domain of the second layer beliefs. We are permitting player $i$ to believe that strategies of the other players (points in $\prod_{j \neq i} A_{j}$ ) would be correlated with some first layer beliefs of the other players (points in $\underset{j \neq i}{\mathbb{i}} S_{j}^{1}$ ). This point will be more obvious when we impose the condition that player $i$ believes player $j$ is rational in the next section

Just as $s_{j}^{1}$ was uncertain to player $i$, so is $s_{j}^{2}$ and so on. Hence each of these layers of beliefs of player $j$ is uncertain to player $i$ and $i$ must successively have priors in:

Definition 3.8: $\quad S_{i}^{\ell}=\Delta\left(\underset{j \neq i}{\operatorname{II} A_{j}} \times \underset{j \neq i}{\operatorname{II}} S_{j}^{\ell-1}\right)=\Delta\left(S_{i}^{0} \times \underset{j \neq i}{\operatorname{II}} S_{j}^{\ell-1}\right)$.

As before, we are allowing player i to believe that the strategies of the other players may be correlated with their $\ell-1$ th layer beliefs. Beginning with the basic uncertainty $\underset{j \neq i}{\prod_{j}} A_{j}$, player $i$ 's stream of priors is an infinite recursion of beliefs. We assume that a Bayesian player $i$ is completely 
characterized by his infinite recursion of beliefs (equivalently, his type or psychology) which is a point in:

Definition 3.9: $s_{i}^{\infty}=\left\{\left(s_{i}^{1}, s_{i}^{2}, \ldots,\right) \in \prod_{\ell \geq 1} s_{1}^{\ell}:\left(s_{i}^{1}, s_{i}^{2}, \ldots\right)\right.$ satisfies the minimum consistency requirement\}.

The minimum consistency requirement, discussed in detail in Appendix A, simply requires that if the probability of an event $E$ may be computed using i's \& th layer belief, $s_{i}^{\ell}$, or his $m$ th layer belief, $s_{i}^{m}$, they must give the same number.

The reader may wonder if we have exhausted all the uncertainty of player $i$. By extending our earlier argument, it may seem that since $s_{j}^{\infty}$ is unknown to player $i$, he must have a prior on $\underset{j \neq i}{\pi} A_{j} \times \underset{j \neq i}{\prod} S_{j}^{\infty}$. Such a prior would be. a point in $\Delta\left(S_{i}^{0} \times \prod_{j \neq i} S_{j}^{\infty}\right)$ as before. That is, player $i$. should have a prior on the infinite recursion of beliefs of the other players as well. The answer to this question is given by the fundamental mathematical result proven in Armbruster and Böge (1979), Böge and Eisele (1979) and Mertens and Zamir (1985):

Theorem 3.1: $\forall_{i}, S_{i}^{\infty}$ is compact and metric in the topology induced by the product topology on $\underset{\ell \geq 1}{\operatorname{II}} S_{i}^{\ell}$. Moreover, $\forall i$ there exists a canonical homeomor-

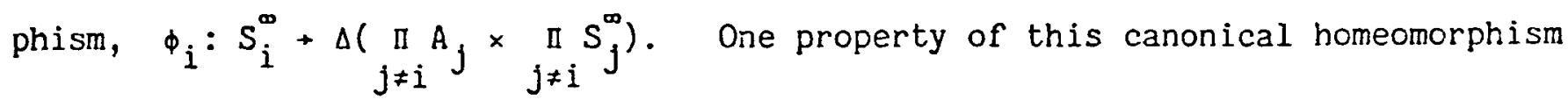
is that $\operatorname{marg}_{s_{i}}\left[\phi_{i}\left(s_{i}^{\infty}\right)\right]=s_{i}^{1}$.

Proof: See one of the above sources.

Q.E.D.

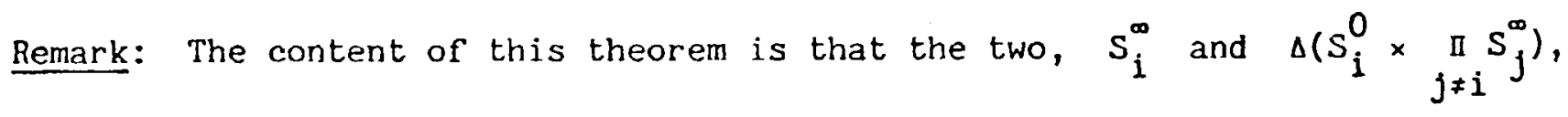
are of the "same size" (homeomorphic) and although one might consider another layer of prior on $s_{i}^{0} \times \prod_{j \neq i} s_{j}^{\infty}$, it would be redundant as this information is 
already contained in $S_{i}^{\infty}$. Alternatively, a reinterpretation of player i's type of infinite layers of belief, is that it is in itself a prior on $\operatorname{II}_{j \neq i} A_{j}$ as well as the infinite layers of beliefs of all the other players. Moreover, the theorem allows us to define the universal domain of uncertainty for player $i$, based on the basic uncertainty space $\underset{j \neq i}{\pi A_{j}}$, to be $\underset{j \neq i}{\operatorname{In} A_{j}} \times \underset{j \neq i}{\mathbb{a}} S_{j}^{\infty}$. It can be interpreted as saying that this space exhausts all that is uncertain, to agent - $i$, about the environment when the basic space of uncertainty is $\underset{j \neq i}{A_{j}}$. As a result, instead of the sequence of beliefs we generated earlier, the standard Bayesian approach can be applied by taking the space $S_{i}=\underset{j \neq i}{\prod_{j}} \times \underset{j \neq i}{\Pi S_{j}^{\infty}}$ as the given domain of uncertainty and then the Bayesian player $i$ must have a prior on this space.

The canonical homeomorpinism allows us to speak of $s_{i}^{\infty}$, the type of the agent $i$, and his prior on $\underset{j \neq i}{\operatorname{II}} A_{j} \times \underset{j \neq i}{\mathbb{I}} S_{j}^{\infty}$ interchangeably. Hence, a type of player $i$ uniquely determines the prior of player $i$ on the state of the basic uncertainty and the types (or states) of the other agents. If an agent is of type $s_{i}$, his prior on $\underset{j \neq i}{\operatorname{If}} A_{j} \times \underset{j \neq i}{\operatorname{II}} s_{j}^{\infty}$ is given by $\phi_{i}\left(s_{i}^{\infty}\right)$. Consequently, his prior on $\underset{j \neq i}{\text { II }} A_{j}$ can be recovered using the canonical homeomorphism and taking the marginal of $\phi_{i}\left(s_{i}^{\infty}\right)$ on $\underset{j \neq i}{\pi} A_{j}$. Another feature of $\phi_{i}\left(s_{i}^{\infty}\right)$ which we use of extensively below is the marginal of $\phi_{i}\left(s_{i}^{\infty}\right)$ on $s_{j}^{\infty}$. This is player i's prior on the possible types of player $j$, equivalently, it is player i's prior on the infinite recursion of beliefs held by player $j$. In particular, the set supp marg $s_{j}^{\infty} \phi_{i}\left(s_{i}^{\infty}\right)$ (i.e. the support of the marginal on $s_{j}^{\infty}$ of player i's 
prior) represents the set of types which player $i$ believes player $j$ can be.

We are now in a position to define:

Definition 3.10: Given a game $r$, we define the Bayesian decision problem associated with $\Gamma$ when player i's beliefs are given by $s_{i}^{\infty} \in S_{i}^{\infty}$ as:

(i) $S_{i}=A_{-i} \times S_{-i}^{\infty} ;$ (ii) $A_{i}$ is the same as $A_{i}$ for $r$;

(ii) $u_{i}\left(a_{i}, s_{i}\right)=\bar{U}_{i}\left(a_{i}, \operatorname{Proj}_{A_{-i}}\left(s_{i}\right)\right) ;$ and (iv) $P_{i} \varepsilon \Delta\left(s_{i}\right)$

is given by $\phi_{i}\left(s_{i}^{\infty}\right)$, where $\phi_{i}$ is the canonical homeomorphism between

$S_{i}^{\infty}$ and $\Delta\left(A_{-i} \times S_{-i}^{\infty}\right)=\Delta\left(S_{i}\right)$

Remark: We have therefore defined the universal domain of uncertainty of player $i$. to be the strategy sets as well as the infinite recursion of beliefs for the other piayers. The utility function is simply the payoff function in the original garne since $\operatorname{Proj}_{A_{-i}}\left(s_{i}\right) \varepsilon A_{-i}$ is just the strategy choices of the other players.

When player i's beliefs are given by $s_{i}^{\infty} \varepsilon S_{i}^{\infty}$, the natural prior on the universal space of uncertainty is given by Theorem $3.1: \phi_{i}\left(s_{i}^{\infty}\right)$ which is a measure on $\underset{j \neq i}{\square} A_{j} \times \underset{j \neq i}{\Pi S_{j}^{\infty}}=S_{i}$. It seems that the only relevant probability distribution for player $j$ is the $\operatorname{marg}_{A_{-i}}\left[\phi_{i}\left(s_{i}^{\infty}\right)\right]$, since: $v\left(a_{i}, \phi_{i}\left(s_{i}^{\infty}\right)\right)=$ $\int_{S_{i}} U_{i}\left(a_{i}, s_{i}\right) d\left[\phi_{i}\left(s_{i}^{\infty}\right)\right]\left(s_{i}\right)=\int_{A_{-i}} \bar{U}_{i}\left(a_{i}, a_{-i}\right) d\left[\operatorname{marg}_{A_{-i}}\left[\phi_{i}\left(s_{i}^{\infty}\right)\right]\right]$. This seems to tell us that the only important part of $\mathbf{s}_{i}^{\infty}$ is the first order belief. We shall see that this is not so. In fact, in the next sections we show how one can obtain several different kinds of behavior and solution concepts by imposing restrictions on the possible $s_{i}^{\infty}$ 's. By an abuse in notation, we define 
Definition 3.11: $v\left(a_{i}, \phi_{i}\left(s_{i}^{\infty}\right)\right)=v\left(a_{i}, s_{i}^{\infty}\right)$. .

In summary, the central assumption of the Bayesian approach is:

Axiom [B]: The decision player $i$ faces in $\Gamma$ of Def. 3.1 is the same as the Bayesian decision problem associated with $\Gamma$, given his infinite recursion of beliefs $s_{i}^{\infty}$, of Definition 3.10 .

4. THE BAYESIAN FOUNDATION OF SOLUTION CONCEPTS

Holding the strategy sets of each player constant, a game $\Gamma$ is simply given by the payoff function. Hence the space of games is the space of all $n-$ tuples of payoff functions. A solution concept then maps each game into subsets of the strategy sets of players -- the outcomes of the game which game theorists believe would or should occur when a given game is played.

Definition 4.1: Solution Concepts. Let $G$ be the n-product of the space of all continuous functions from $\prod_{i=1}^{n} A_{i}$ into the real line. $G$ is the space of games, holding the strategy sets constant. A solution concept $\Sigma$ is then a correspondence $\Sigma: \quad G \rightarrow \prod_{i=1}^{n} A_{i}$.

Hence given a game $\Gamma \varepsilon G, \quad \Sigma(\Gamma) \subset \underset{i=1}{n} A_{i}$ is the solution concept. For example, $\Sigma$ could be the Nash equilibrium mapping and $\Sigma(\Gamma)$ the set of Nash equilibria of the game $\Gamma$.

Since we have taken as an axiom that the decision faced by players in $r$ is the same as the Bayesian decision problem, we are led to investigate the beliefs of player $i$ (i.e. restrictions on $s_{i}^{\infty}$ ) and how he behaves given these beliefs. In particular, given a game $\Gamma$ and a solution concept $\Sigma$, what assumptions would result in player $i$ taking an action consistent with the 
solution concept -- that is, choose a strategy in $\operatorname{Proj}_{A_{i}} \Sigma(r)$. Similarly, what assumption on beliefs and behavior for all the players would lead them to choose a vector of strategies which lies in $\Sigma(\Gamma)$.

We impose the following axiom from the beginning:

Axiom [B.R.]: Given Axiom [B], when player $i$ has beliefs $s_{i}^{\infty}$, he is Bayesian Rational in the sense of Def. 3.2 .

Thus, given a stream of priors, player i will choose a strategy to maximize his expected subjective utility. Axioms [B] and [B.R.] cannot be objectionable if one is sympathetic towards the Bayesian approach and if one takes the simultaneity of $\Gamma$ seriously. The remaining task is to find axioms on the infinite recursions of beliefs of players which would lead them to behave consistently with a given solution concept.

A more adventurous approach would be to lay down axioms on these priors which one is comfortable imposing on all games and to derive the resultant behavior of the Bayesian rational players, calling this a solution concept. We feel that it is premature for us to attempt this and currently lean towards tailoring assumptions on beliefs on a case by case basis.

5. THE BAYESIAN FOUNDATIONS OF ITERATIVELY UNDOMINATED STRATEGIES AND RATIONALIZABLE BEHAVIOR

We consider two axioms on the beliefs of Bayesian rational players and derive solution concepts which are consistent with them.

The first axiom [R] is that player $i$ believes that Bayesian rationality of all the players is common knowledge. In the absence of any other restriction, we show that the player must then take a strategy which is rationalizable against correlated strategies of other players. This is equivalent to iterative elimination of strictly dominated strategies. We also show that every action 
which is rationalizable against correlated strategies can be supported by an infinite recursion of beliefs for piayer $i$ which is consistent with "rationality is common knowledge." Hence, if this axiom is the only one the game theorist is willing to impose on beliefs, then his solution concept must coincide with the iterative elimination of strictly dominated strategies.

The second axiom [I] is "players act independently is common knowledge." Such a restriction on the beliefs of a player will lead him to play a strategy which is rationalizable in the sense of Bernheim (1985) and of Pearce (1985) when combined with Axioms[B], [B.R.] and $[R]$. Each rationalizable strategy can also be supported by beliefs consistent with the four axioms. Hence if these four are the only restrictions which one is willing to place on the beliefs, the solution concept one has to use must be the Bernheim and Pearce notion of rationalizable.

Definition 5.1: Iteratively Undominated Strategies or Rationalizable Strategies Against Correlated Strategies of Other Players

Let $A_{i}^{0}=A_{i}$

$$
\begin{aligned}
& A_{i}^{l}=\left\{a_{i} \varepsilon A_{i}: \text { There exists } \mu \varepsilon \Delta\left(\prod_{j \neq i} A_{j}^{l-1}\right)\right. \text {, s.t. } \\
& \left.\int_{A_{-i}} \bar{U}_{i}\left(a_{\cdot i}, a_{-i}\right) d \mu=\operatorname{Max}_{\hat{a}_{i} \varepsilon A_{i}} \int_{A_{-i}} \bar{U}_{i}\left(\hat{a}_{i}, a_{-i}\right) d \mu\right\}
\end{aligned}
$$

The iteratively undominated strategies of player $i$ are $\underset{\ell \geq 0}{n} A_{i}^{\ell}$

Remark: (i) Note that if $a_{i} \varepsilon A_{i}^{l}$ is not a best response against some

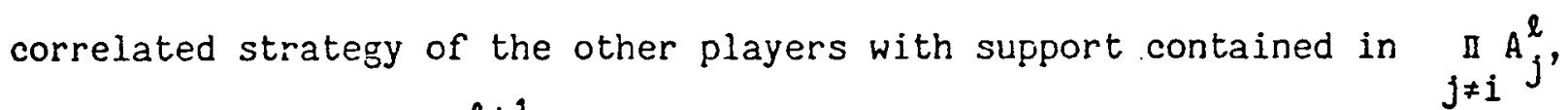
then $a_{i}$ is not in $A_{l}^{\ell+1}$ and is eliminated in the $l \underline{\text { th }}$ round.

(ii) A strategy $a_{i} \varepsilon A_{i}^{l}$ is strictly dominated by a mixed strategy $\mu \varepsilon \Delta\left(A_{i}^{l}\right)$ against $\underset{j \neq i}{I} A_{j}^{\ell}$ if ror every $a_{-i} \varepsilon \underset{j \neq i}{\pi} A_{j}, \int_{A_{i}} \bar{U}_{i}\left(\hat{a}_{i}, a_{-i}\right) d \mu>\bar{U}_{i}\left(a_{i}, a_{-i}\right)$. It should be clear that if $a_{i} \varepsilon A_{i}^{l}$ is strictly dominated by some $\mu \varepsilon \Delta\left(A_{i}^{l}\right)$ against $\underset{j \neq i}{\|} A_{j}^{l}$, it would not be in $A_{i}^{\ell+1}$. Since $\mu$ strictly dominates $a_{i}$, 
there must be a pure strategy in the support of $\mu$ which gives a higher payoff than $a_{i}$ against $a_{-i}$.

The converse requires proof: that if $a_{i} \varepsilon A_{i}^{\ell}$ and $a_{i} t A_{i}^{\ell+1}$, then there exists $\mu \in \Delta\left(A_{i}^{l}\right)$ such that for every $a_{-i} \varepsilon \underset{j \neq i}{\pi} A_{j}^{l}, \int_{A_{i}} \vec{U}_{i}\left(\hat{a}_{i}, a_{-i}\right) d \mu>\vec{U}_{i}\left(a_{i}, a_{-i}\right)$. This is contained in the Appendix to Pearce (1984) and requires a fixed-point type argument.

\section{Definition 5.2: Knowledge of Eayesian Rationality}

$\forall i, \quad i$ knows everyone is rational

$$
\begin{aligned}
\Leftrightarrow s_{i}^{\infty} \varepsilon K_{i}^{l} & =\left\{s_{i}^{\infty}:\left(a_{j}, s_{j}^{\infty}\right) \quad \varepsilon \operatorname{supp} \operatorname{marg}_{A_{j} \times s_{j}^{\infty}\left[\phi_{i}\left(s_{i}^{\infty}\right)\right]}\right. \\
& \left.\Rightarrow V\left(a_{j}, s_{j}^{\infty}\right)=\underset{a_{j} \varepsilon A_{j}}{\max } V\left(\hat{a}_{j}, s_{j}^{\infty}\right)\right\}
\end{aligned}
$$

$\forall i, . i$ knows everyone (knows everyone) ${ }^{l-1}$ is rational

$$
\begin{gathered}
\Leftrightarrow s_{i}^{\infty} \varepsilon K_{i}^{\ell}=\left\{s_{i}^{\infty} \varepsilon K_{i}^{\ell-1}: s_{j}^{\infty} \varepsilon \operatorname{supp} \operatorname{marg}_{s_{j}^{\infty}}\left[\phi_{i}\left(s_{i}^{\infty}\right)\right]\right. \\
\left.\Rightarrow s_{j}^{\infty} \varepsilon K_{j}^{\ell-1}\right\}
\end{gathered}
$$

Remark: When the beliefs of player $i, s_{i}^{\infty}$, then $\phi_{i}\left(s_{i}^{\infty}\right)$ is his prior on the strategies and infinite recursion of deliefs of the other players by Axiom [B]. $s_{i}^{\mathbf{m}} \varepsilon K_{i}^{1}$ implies that if player $i$ believes that it is possible for player $j$ to take strategy $a_{j}$ when he has beliefs $s_{j}^{\infty}$ (that is, $\left(a_{j}, s_{j}^{\infty}\right) \varepsilon$ supp marg $\left.{ }_{A_{j} \times S_{j}^{\infty}}\left(\phi_{i}\left(s_{i}^{\infty}\right)\right]\right)$, then $a_{j}$ must maximize player $f^{\prime} s$ expected subjective utility given j's prior $\phi_{j}\left(s_{j}^{\infty}\right)$.

In other words, player $i$ believes that player $j$ is Bayesian rational or satisfies Axioms [B] and [B.R.]. Higher levels of knowledge of rationality are simply defined inductively. Hence $s_{i}^{\infty} \varepsilon K_{i}^{\ell}$ implies that player $i$ believes 
that player $\mathrm{J}^{\prime} \mathrm{s}$ beliefs are in $\mathrm{K}_{\mathrm{j}}^{\ell-1}$. That is, $i$ believes that $\mathrm{j}$ believes rationality is known up to $\ell-1$ layers. This definition captures the intuitive notion of common knowledge. A more thorough discussion of this and comparison with Aumann (1976) is provided in Tan and Werlang (1986).

Axion [R]: Bayesian Rationality is Common Knowledge.

$\forall i, \quad s_{i}^{\infty} \varepsilon \underset{\ell \geq 1}{n} K_{i}^{\ell}$.

Lemma 5.1 states that if player i believes that everyone (knows everyone $)^{\ell-1}$ is rational, i.e. $s_{i}^{\infty} \varepsilon K_{i}^{\ell}$, then any of the strategies he believes the other player may play -- strategies in the support of his prior. on the strategies of the other players $\left(a_{-i} \varepsilon\right.$ supp $\left.\operatorname{marg}_{A}\left[\phi_{i}\left(s_{i}^{\infty}\right)\right]\right)$ - must survive $\&$ rounds of elimination of strictly dominated strategies. Moreover, Theorem 5.1 states that rational player $i$ then chooses a strategy which survives $\ell+1$ rounds of elimination of strictly dominated strategies.

Lemma 5.1: $\forall \ell, \forall i, s_{i}^{\infty} \varepsilon K_{i}^{l} \Rightarrow$ supp $\operatorname{marg}_{A_{-i}}\left[\phi_{i}\left(s_{i}^{\infty}\right)\right] \subset A_{-i}^{\ell}$.

\section{Proof of Lemma 5.1: By induction}

Let $\quad s_{i}^{\infty} \varepsilon K_{i}^{1}$. Then $\left(a_{j}, s_{j}^{\infty}\right) \varepsilon \operatorname{supp} \operatorname{marg}_{A_{j} \times S_{j}^{\infty}\left[\phi_{i}\left(s_{i}^{\infty}\right)\right]}$

$$
\begin{aligned}
& \Rightarrow V\left(a_{j}, s_{j}^{\infty}\right)=\max _{j} V\left(\cdot, s_{j}^{\infty}\right) \\
& \Rightarrow a_{j} \in A_{j}^{\prime} \text { since } \operatorname{marg}_{A_{-j}}\left[\phi_{j}\left(s_{j}^{\infty}\right)\right]
\end{aligned}
$$

is the required $\mu \varepsilon \Delta\left(A_{-j}^{0}\right)$ in the definition $A_{j}^{1}$. Since this is true for all $j \neq i$, then $a_{-i} \in$ supp $\operatorname{marg}_{A_{-i}}\left[\phi_{i}\left(s_{i}^{\infty}\right)\right] \Rightarrow a_{-i} \varepsilon A_{-i}^{1}$. Hence supp $\operatorname{marg}_{A_{-i}}\left[\phi_{i}\left(s_{i}^{\infty}\right)\right] \subset A_{-i}^{l}:$ Assume that $s_{i}^{\infty} \in K_{i}^{\ell} \Rightarrow \operatorname{supp} \operatorname{marg}_{A_{-i}}\left[\phi_{i}\left(s_{i}^{\infty}\right)\right] \subset A_{-i}^{l}$ 
We shall show that $s_{i}^{\infty} \in K_{i}^{l+1} \Rightarrow$ supp $\operatorname{marg}_{A_{-i}}\left[\phi_{i}\left(s_{i}^{\infty}\right)\right] \subset A_{-i}^{l+1}$.

Let $s_{i}^{\infty} \varepsilon K_{i}^{\ell+1}$. Then for $\left(a_{j}, s_{j}^{\infty}\right) \in \operatorname{supp} \operatorname{marg}_{A_{j} \times S_{j}}\left[\phi_{i}\left(s_{i}^{\infty}\right)\right]$, we know by the definition of $K_{i}^{\ell+1}$ that $S_{j}^{\infty} \in K_{j}^{\ell}$. Hence by the inductive hypothesis, supp $\operatorname{marg}_{A_{-j}}\left[\phi_{j}\left(s_{j}^{\infty}\right)\right] \subset A_{-j}^{l} \cdot$ Now, $s_{i}^{\infty} \varepsilon K_{i}^{\ell+1} \subset K_{i}^{1}$ by definition, so that $V\left(a_{j}, s_{j}^{\infty}\right)=\max _{A_{j}} V\left(\cdot, s_{j}^{\infty}\right)$. Hence, $a_{j} \varepsilon A_{j}^{l+1}$ since $\operatorname{marg}_{A_{-j}}\left[\phi_{j}\left(s_{j}^{\infty}\right)\right] \varepsilon \Delta\left(A_{-j}^{l}\right)$ is the required $\mu \varepsilon \Delta\left(A_{-j}^{l}\right)$ in the definition of $A_{j}^{l+1}$. Since this holds for all $j, a_{-i} \varepsilon \operatorname{supp} \operatorname{marg}_{A_{-i}}\left[\phi_{i}\left(s_{i}^{\infty}\right)\right] \Rightarrow a_{-i} \varepsilon A_{-i}^{l+1}$.

$\therefore$ supp $\operatorname{marg}_{A_{-i}}\left[\phi_{i}\left(\dot{s}_{i}^{\infty}\right)\right] \subset A_{-i}^{l+1}$

Theorem 5.1: If player $i$ is Bayesian rational and $s_{i}^{\infty} \varepsilon k_{i}^{\ell}$, then he chooses an action $a_{i} \in A_{i}^{l+1}$.

\section{Proof of Theorem 5.1:}

$s_{i}^{\infty} \in K_{i}^{l} \Rightarrow \operatorname{supp} \operatorname{marg}_{A_{-i}}\left[\phi_{i}\left(s_{i}^{\infty}\right)\right] \subset A_{-i}^{l}$. Hence $\operatorname{marg}_{A_{-i}} \phi_{i}\left(s_{i}^{\infty}\right) \in \Delta\left(A_{-i}^{l}\right)$.

Since $i$ is rational, he chooses an action $a_{i}$

s.t.

$$
\begin{aligned}
V\left(a_{i}, s_{i}^{\infty}\right) & =\max V\left(\cdot, s_{i}^{\infty}\right) \\
& =\int_{A_{i}} U_{i}\left(\cdot, a_{-i}\right) d\left[\operatorname{marg}_{A_{-i}} \cdot \phi_{i}\left(s_{i}^{\infty}\right)\right] \\
& =\int_{A_{-i}^{l}} U_{i}\left(\cdot, a_{-i}\right) d\left[\operatorname{marg}_{A_{-i}} \phi_{i}\left(s_{i}^{\infty}\right)\right]
\end{aligned}
$$

since the support of $\operatorname{marg}_{A_{-i}} \Phi_{i}\left(s_{i}^{\infty}\right) \subset A_{-i}^{l}$ by Prop. 4.1. Hence $a_{i} \in A_{i}^{l+1}$.

Q.E.D. 
The following is immediate:

Theorem 5.2: Under Axioms [B], [B.R.] and [R], player $i$ chooses an action $a_{i}$

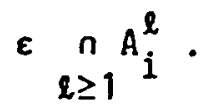

Remark: 5.2 states that rationality is common knowledge leads to a Bayesian rational agent taking a strategy which is an iteratively undominated strategy. Hence if these three axioms are imposed, the solution concept must survive iterative dominance.

Does rationality impose more restrictions than what is implied by Theorem 5.2? Is the solution concept which is consistent with Axiomx [B], [B.R.] and [R] a strict subset of the iteratively undominated strategies? The answer, which is no, is contained in the following two results. Lemma 5.2 states that for every strategy which survives $\ell+1$ rounds of elimination, there is a belief $s_{i}^{\infty}$ for player i which is consistent with "rationality is known to level $\ell$," for which that action is a best response. Theorem 5.3 then states that every strategy which survives all rounds of elimination can be rationalized by some prior which is consistent with "rationality is common knowledge."

These two results then imply that if $k_{i}^{\ell}$ is all one is willing to assume about the beliefs of the players, we must be satisfied with only $\ell+1$ rounds of elimination, and if "rationality is conmon knowledge" is all we want to assume, our solution concept must coincide with iterated dominance. Notice that Lemma 5.2 implies that rationality by itself, or knowledge of rationality up to some finite level, it not sufficient to give rise to iteratively undominated behavior in general. The full common knowledge assumption is required.

The proofs of these two results, as well as several technical lemmata on measurability which are reguired for their proof are contained in Appendix $B$. The technical lemmata may be of interest for others who wish to apply this 
framework.

Lema 5.2: $\forall i, \forall i, \forall a_{i} \in A_{i}^{l+1}$, there exists $s_{i}^{\infty} \varepsilon K_{i}^{\ell}$ such that $a_{i} \in \arg \max v\left(\hat{a}_{i}, s_{i}^{\infty}\right)$.

$a_{i} \varepsilon A_{i}$

Proof: See Appendix B.

Q.E.D.

Lemma 5.3: Let $a_{i} \varepsilon \underset{\ell \geq 1}{n} A_{i}^{l}$. Then there exists $s_{i}^{\infty} \in S_{i}^{\infty}$ such that

$s_{i}^{\infty} \varepsilon \prod_{\ell \geq 1}^{n} K_{i}^{\ell}$ and $v\left(a_{i}, s_{i}^{\infty}\right)=\max _{\hat{a}_{i} \varepsilon A_{i}} v\left(\hat{a}_{i}, s_{i}^{\infty}\right)$

Proof: See Appendix B.

Q.E.D.

We now add independence to rationality and state the analogous results pertaining to rationalizable strategies in the sense of Bernheim (1984) and Pearce (1984). It should be clear that in a precise sense, rationalizability requires more assumptions about the beliefs about each player than iterative dominance. See, however, the discussion of results before the conclusion for our subjective view of the two solution concepts. We let $\mathbb{i}_{i=1}^{N} \Delta\left(A_{i}\right)$ denote the set of probability measures, on $i_{i=1}^{N} A_{i}$, which are products of measures on each $A_{i}$.

Definition 5.3: Rationalizable Strategies (Bernheim, 1984 and Pearce, 1984)

Let $R_{i}^{0}=A_{i}$

$$
\begin{aligned}
R_{i}^{l}= & \left\{a_{i} \in A_{i}: \text { there exists } \mu \varepsilon \underset{j \neq i}{\Delta\left(R_{j}^{l-1}\right) \text { s.t. }}\right. \\
& \left.\int_{A_{-i}} \bar{U}_{i}\left(a_{i}, a_{-i}\right) d \mu=\underset{a_{i} \varepsilon A_{i} A_{-i}}{ } \int_{i}\left(\hat{a}_{i}, a_{-i}\right) d \mu\right\}
\end{aligned}
$$

The Rationalizable Strategies of player $i$ are $\underset{\ell \geq 0}{n} R_{i}^{\ell}$. 


\section{Definition 5.4: Knowledge of Independence.}

Player $i$ believes everyone acts independently.

$$
\Leftrightarrow s_{i}^{\infty} \in I_{i}^{1}=\left\{s_{i}^{\infty} \in s_{i}^{\infty}: \operatorname{marg}_{A} \phi_{i}\left(s_{i}^{\infty}\right) \varepsilon \underset{j \neq i}{\left.\Delta\left(A_{j}\right)\right\}}\right.
$$

Player $i$ believes (everyone knows) ${ }^{2-1}$ is rational

$$
\Leftrightarrow s_{i}^{\infty} \varepsilon I_{i}^{\ell}=\left\{s_{i}^{\infty} \varepsilon s_{i}^{\infty}: s_{j}^{\infty} \varepsilon \operatorname{supp} \underset{s_{j}^{\infty}}{\operatorname{marg}}\left[\phi_{i}\left(s_{i}^{\infty}\right)\right] \Rightarrow s_{j}^{\infty} \varepsilon I_{j}^{\ell-1}\right\}
$$

Axiom [I]: Independence is Common Knowledge if

$$
\forall i, \quad s_{i}^{\infty} \varepsilon \underset{\ell \geq 1}{n} I_{i}^{\ell}
$$

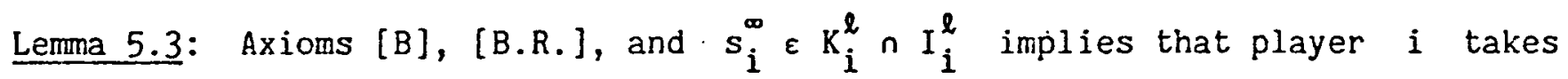
an action in $\mathrm{R}_{\mathrm{i}}^{\ell+1}$.

Theorem 5.4: Axioms [B], [B.R.], [R] and [I] imply that player i takes a rationalizable strategy.

Lemma 5.4: $\forall i, \forall \ell, \quad \forall_{i} \varepsilon A_{i}^{\ell+1}$, there exists $s_{i}^{\infty} \varepsilon K_{i}^{\ell} \cap I_{i}^{\ell}$ such that $a_{1} \varepsilon \arg \max V\left(\hat{a}_{i}, s_{i}^{\infty}\right)$.

$$
\hat{a}_{i} \in A_{i}
$$

Theorem 5.5: Let $a_{i} \varepsilon \underset{\ell \geq 1}{n} R_{i}^{\ell}$. Then there exists $s_{i}^{\infty} \varepsilon \underset{\ell \geq 1}{n}\left(K_{i}^{\ell} \cap I_{i}^{\ell}\right)$ such that $v_{i}\left(a_{i}, s_{i}^{\infty}\right)=\underset{a_{i} \varepsilon A_{i}}{\max } V\left(\hat{a}_{i}, s_{i}^{\infty}\right)$

The proofs of these four results are straightforward adaptations of the proofs for the analogous results for iterative dominance.

Again, if Axioms [B], [B.R.], [R] and [I] are all the restrictions that one is willing to impose on the priors of the players, then the solution concept one must use coincides with rationalizability. By Theorem 5.5, these axioms do not 
restrict behavior any further.

\section{THE BAYESIAN EOUNDATIONS OF NASH EQUILIBRIUM}

This section is taken from Werlang (1986).

The Nash concept is by far the most widely accepted solution concept. It has frequently been argued that it should be a necessary property of any solution concept. Hence, many of the newly introduced solution concepts discussed in the introduction and subsets of the Nash solution concept for any game.

We saw in Section 5 that the four axioms we discussed earlier are not sufficient to generate Nash benavior. If a Bayesian Rational player's beliefs were consistent with rationality and independence being comron knowledge, then he may play any strategy that is rationalizable if we know nothing else about his beliefs. These strategies may not be Nash equilibrium strategies.

\subsection{COORDINATION AND NASH BEHAVIOR}

Our first result on Nash behavior is just a formalization of the usual justification for the Nash concept. This is expressed in the classical quote below, taken from Luce and Raiffa (1957, page 173):

"Nonetheless, we continue to have one very sirong argument for equilibrium points: if our non-cooperative theory is to lead to an n-tuple of strategy choices, and if it is to have the property that knowledge of the theory does not lead one to make a choice different from the dictated by the theory, then the strategies isolated by the theory must be equilibrium points."

As one can see this justification is a simple restatement of the definition of a Nash equilibrium. The Nash equilibria are the only n-tuple of actions which are consistent with common knowledge of the actions taken, as well as of rationality. If one takes a theory to be single-valued, then the Nash equilibria are the only n-tuples of actions which are consistent with common knowledge of 
the actions taken, as well as of rationality.

Fix a game $I \in G$. The formalization of the knowledge of a theory (equivalently, solution concept) by the players, is simply the fact that the actions this theory predicts are the only actions which are considered possible by the players. The notation is the same as in sections three and four. In particular, if one wants to refer to "knowledge of a theory $\Sigma(\Gamma)$," where $\Sigma(\Gamma)$ is contained in $A=A_{1} \times \ldots \times A_{n}$, we have:

Definition 6.1.1: Given $\Sigma(\Gamma)$ contained in $A$, a theory, we say that player i knows a theory $\Sigma(\Gamma)$ when $s_{i}^{\infty} \varepsilon \varepsilon_{i}^{1}=\left\{s_{i}^{\infty} \varepsilon S_{i}^{\infty}: \operatorname{Proj}_{A_{-i}} \Sigma(\Gamma)>\operatorname{supp} \operatorname{marg}_{A_{-i}}\left[\phi_{1}\left(S_{i}^{\infty}\right)\right]\right\}$.

In other words: player $i$ knows a theory. when he thinks other players are going to fulfill their role in this theory.

Definition 6.1.2: A theory $\Sigma(r)$ is common knowledge in the eyes of player i if: $s_{i}^{\mathbf{0}} \varepsilon \underset{\ell \geq 1}{n} \Sigma_{i}^{\ell}$, where: $\Sigma_{i}^{1}$ is given above, and $\forall \ell \geq 2: \Sigma_{i}^{\ell}=\left\{s_{i}^{\infty} \varepsilon \Sigma_{i}^{\ell-1}: \forall k \neq i: s_{k}^{\infty} \varepsilon \operatorname{supp} \operatorname{marg}_{s_{k}^{\infty}}\left[\phi_{i}\left(s_{i}^{\infty}\right)\right] \Rightarrow s_{k}^{\infty} \varepsilon \Sigma_{k}^{\ell-1}\right\}$. Axiom [T]: $\forall i$, the theory $\Sigma(\Gamma)$ is common knowledge in the eyes of player $i$. Theorem 6.1.1: Assume that $\Sigma(\Gamma)=\left\{\left(\tilde{a}_{1}, \ldots, \tilde{a}_{n}\right)\right\}$, that is to say, $\Sigma$ is a single-valued solution concept for $\Gamma$ under Axioms [B], [B.R], and $[T]$. Then $\Sigma(r)$ is a Nash equilibrium. Moreover, any Nash equilibrium is compatible with common knowledge of the theory and common knowledge of rationality.

Proof: Since player $i$ knows that player $k$ is rational and player $k$ knows the theory, it follows that $\tilde{a}_{k}$ is a best response to $\tilde{a}_{-k}$, for all $k \neq i$. To check that $\tilde{a}_{i}$ is a best response to $\tilde{a}_{-i}$, it is enough to carry the same argument above one more layer. Observe that it was necessary to use only 
$s_{i}^{\infty} \varepsilon k_{i}^{2} \cap \varepsilon_{i}^{3}$. The second part of the theorem is immediate.

Q.E.D.

The result above gives one set of assumptions on beliefs and behaviors which justifies the Nash equilibrium concept. This set of assumptions is the main thrust of Nash equilibrium. However, we feel that the theorem above also shows the weakness of the concept. In fact, the Nash equilibrium is played when the actions which are going to be taken are common knowledge, before they have been taken. It shows the strong need for coordination in obtaining Nash behavior. This is the role played by several of the "stories" to justify Nash equilibrium behavior: they are mere coordination mechanisms. Famous examples of these stories are the "book of Nash" and the "gentlemen's club." The former is well known. The latter is simply a revised version of the former: every player should belong to the same gentlemen's club, where the club's statute tells them how to behave in a game-theoretic situation. As they are gentlemen (and very possibly English), they all give their word of honor they will follow this statute (Binmore (1984)) and everyone believes everyone's word of honor.

From the proof of Theorem 6.1.1, it was not necessary to assume common knowledge of rationality and the solution concept. Rationality known to two layers and the solution concept known to three were sufficient to show that the solution concept had to be a Nash equilibrium.

Notice, however, that this is slightly stronger than the "knowledge of the theory" in the quote from Luce and Raiffa above.

\subsection{THE KNOWLEDGE THAT PLAYERS MAY PLAY NASH EQUILIBRIUM}

In Subsection 6.1, we generated Nash behavior by formalizing the classic justification -- common knowledge of a theory. Here, we relax that assumption somewhat by just requiring that players believe that the other players may play the Nash equilibrium, instead of must play in 6.1 . 
It is well hucwn that in the Cournot Duopoly with linear demand and constant marginal cost, the unique Nash equilibrium is also the unique rationaliaable equilibrium. However, when there are three firms, although there is a unique Nash equilibrium, there is a continuum of rationalizable equilibria. (See Bernheim (1984) and Moulin (1984).) We show in the context of an example that knowing the other players ray play Nash ziong with Axions $[B],[B, R]$ and $[R]$ results in a Nash equilibrium for the three firm case. This zeneralization however is limited as we show that it does not work for four firms!

Example 6.2.1 (Cournot oligopoly with linear denand and constant narginal costs.) Let there be $n$ identical firms, each of them with naximum capacity 10. Suppose marginal costs are constant and equal to one. The market inverse demand function is given by $P(Q)=\max (10-Q, 0)$. The firms play with quantities in the fashion of Cournot. The strategy set of firm $i$ is: $A_{i}=[0,1]$, with generic elment $q_{i}$. The payoffs are given by the profit functions $\pi_{i}\left(q_{1}, \ldots, q_{n}\right)=P\left(\Sigma q_{k}\right) q_{i}$. Ereferences are lexicographical: payoff functions should be maximized. In case of equality, quantity is minimized. This game has a unique Cournot-Nash solution: all firms produce the guantity $q_{i}=9 /(n+1)$. When $\mathrm{n}=2$ the only rationalizable action for a firm is the Cournot-Nash equilibrium $\mathrm{q}_{i}=9 / 3$ (see Bernheim (1984) and Moulin (1984)). For $\mathrm{n}=3$ the set of rationalizable actions for each firm is the interval $[0,9 / 2]$.

\section{Definition 6.2.1: (Knowledge and Common Knowledge That Other Plavers May Play a}

\section{Nash Theory.) Given a game $\Gamma$ and $\left(\tilde{a}_{1}, \ldots, \tilde{a}_{n}\right)$ a Nash equilibrium (in pure} strategies of this game, we say player i knows that other players may play it, if: $s_{i}^{\infty} \in N_{i}^{1}=\left\{s_{i}^{\infty} \in s_{i}^{\infty}: \tilde{a}_{-i} \varepsilon \operatorname{supp} \operatorname{marg}_{A}\left[\phi_{i}\left(s_{i}^{\infty}\right)\right]\right\}$. In the same way we say that it is common knowledge in the eyes of player $i$ that the Nash theory 
$\left(\tilde{a}_{1}, \ldots, \tilde{a}_{n}\right)$ may be $p l a y e d$ by other players, if $s_{i}^{\infty} \varepsilon{ }_{\ell \geq 1} N_{i}^{\ell}$ where: $\left.\ell \geq 2: \quad N_{i}^{\ell}=\left\{s_{i}^{\infty} \varepsilon N_{i}^{\ell-1}\left|\not k j=1: \quad s_{k}^{\infty} \varepsilon \operatorname{supp} \operatorname{marg}_{S_{k}}\right| \phi_{i}\left(s_{i}^{\infty}\right)\right] \Rightarrow s_{k}^{\infty} \varepsilon N_{k}^{\ell-1}\right\}$.

Proposition 6.2.1: Let the game be as in example 6.2.1, with $\mathrm{n}=3$. Assume that rationality is co: mon knowledge and that the possibility of playing the Cournot equilitrium is also comon knowledge. Then, the only possible action taken by a rational firm is the Cournot-Nash equilibrium (which is $q_{i}=9 / 4$ ).

Proof: The requirement soove is that $s_{i}^{\infty} \in\left(\underset{\ell \geq 1}{n} K_{i}^{\ell}\right) \cap\left(\underset{\ell \geq 1}{n} N_{i}^{\ell}\right)(*)$ and that every player is rational (the sets $N_{i}^{\ell}$ are generated according to Definition 6.2.1, taking as $\left(\tilde{a}_{1}, \ldots, \tilde{a}_{n}\right)$ the triple $\left.(9 / 4,9 / 4,9 / 4)\right)$. First point to notice is that due to the symetry of the Eame, it is enough to concentrate the analysis in one particular firm. We are going to show that the only action which is compatible with rational benavior and condition $\left(^{*}\right)$ is $9 / 4$. Fearrarging $(*)$ : $s_{i}^{\infty} \varepsilon \underset{\ell \geq 1}{\cap}\left(K_{i}^{\ell} \cap N_{i}^{\ell+1}\right)$. This allows us to reinterpret the assumption of the theorem. For example, $\mathrm{K}_{\mathrm{i}}^{1} \cap \mathrm{N}_{\mathrm{i}}^{2}$ means that not only player $\mathrm{i}$ thinks $\mathrm{k}$ is rational, but also that any action $\mathbf{k}$ takes may be rationalized by beliefs which contain the Cournot actions of the other players in the support. One can easily see that $\left(^{*}\right)$ is verified if and only if: (i) i thinks the others may play $(9 / 4,9 / 4)$; and (ii) all actions $i$ thinks $k$ may take have to be rationalized by beliefs which comprehend the Cournot actions in the support, and using the symmetry of the game, every action in this support has to be rationalized by beliefs which comprenend the Cournot actions in the support, and so on. Let us study what happens in each mental interaction described above. Let $q_{i}$ be an action which is a best response to a belief $\mu \in \Delta([0,10] \times[0,10])$. The first thing to notice is that $q_{i} \neq(9 / 2,10)$. In fact, suppose not. One can check that the action $9 / 2$ will give a higher payoff. Also $q_{i} \neq 10$ from the 
assumption that rarginal costs are one: the firm can always produce 0 . Let us go to the sccond round (notice: we still did not use the fact that $(9 / 4,9 / 4$ ) is in the support of $\mu)$. Then $[0,9 / 2]^{2}, \operatorname{supp}[\mu]$, from the analysis above. In this case the response function can be computed ard it is:

$$
q_{i}(\mu)=(1 / 2)\left(9-E_{\mu}\left(\Sigma_{k \neq i} \cdot q_{k}\right)\right)
$$

Let $q_{\text {inf }}$ and $q_{\text {sup }}$ be the infimum and the supremum of the support after the infinite recursion. By the above formula, for every $q \varepsilon \operatorname{supp}[\mu]$ :

$$
q \leq(1 / 2)\left(9-2 q_{\text {inf }}\right)(A) \text {, and } q \geq(1 / 2)\left(9-2 q_{\text {sup }}\right) \quad(B)
$$

But the beliefs which support $q$ must contain $(9 / 4,9 / 4)$ in the support. Thus ineouality (A) must be strict if $q_{\text {inf }} \neq 9 / 4$, and inequality (B) in case $q_{\text {sup }} \neq 9 / 4$. Suppose ore of the strict inequalities above hold. Let us say $(\hat{A})$. One can take $q$ to be $q_{\text {sup }}$ in (A) and $q$ to be $q_{\text {inf }}$ in (B), since tine support is a closed set. Hence: $q_{\text {sup }}<5-q_{\text {inf }}$ and $q_{\text {inf }} \geq 5-q_{\text {sup }}$. This is a contradiction. Thus $q_{\text {inf }}=q_{\text {sup }}=9 / 4$, and the proposition followsQ.E.D.

The result above does not generalize. For the case of four firms we do not obtain the Cournot-Nash equilibrium as the only possible outcome.

Example 6.2.2 (Coimon knowledge of rationality and of the possibility of a Nash theory being played is not enough to obtain Nash equilibrium.) Consider the sane game as above, with $n=4$. In this case the Nash equilibrium is $(9 / 5,9 / 5,9 / 5$, 9/5). We show, for example, that 0 can be an outcome in this game. This follows from the observations in the proof of the proposition above, plus the fact that:

(i) 0 is the best response to a belief which assigns probability $18 / 23$ to $(10 / 3,10 / 3,10 / 3)$, and $5 / 23$ to actions $(9 / 5,9 / 5,9 / 5)$; 
(ii) $10 / 3$ is the best response against a belief which assigns probability $46 / 81$ to $(0,0,0)$ and $35 / 81$ to $(9 / 5,9 / 5,9 / 5)$.

From this example one sees the need to investigate further on the foundations of Nash behavior: the mere common knowledge of the possibility of a Nash theory being played does not imply Mash behavior, even in an example with a unique Nash equilibrium (with or without mixtures) whose actions have the property of being unique best resporses given the actions of the others. The next subsection will present another set of behavioral assumptions which will yield Nash behavior for any two-person game. The assunptions and the main result are taken from Armbruster and Böge (1979).

\subsection{KNOWLEDGE OF OTHER PLAYERS AND NASH EQUILIBRIUM}

We now proceed to investigate other, possibly weaker, sets of assumptions which would lead the players to play a Nash equilibrium. First, let us reinterpret a Nash equilibrium in mixed strategies. The traditional view of a mixed strategy is literally that each player chooses a randomization device which "plays" the mixed strategy. In the Bayesian Framework, an alternative interpretation of a mixed strategy for player $j$ is that it is player i's prior on the strategies of player $j$. Hence, in a mixed strategy Nash equilibrium, instead of each player actually randomizing according to their equilibrium strategies, one could instead have player i's prior to be the equilibrium mixed strategies of the other players.

In this subsection, we provide an alternative assumption which will imply Nash behavior in two-person games. First we have to interpret a mixed strategy Nash equilibrium in a subjective fashion.

Definition 6.3.1: Let $\left(\mu_{1}, \ldots, \mu_{n}\right)$ be a mixed strategy Nash.equilibrium for the game $u$, where $\mu_{i} \varepsilon \Delta\left(A_{j}\right)$. We say that the $n$-tuple of types $\left(s_{j}^{\infty}, \ldots s^{\infty}\right)$ 
plays the Nash equilibrium $\left(\mu_{1}, \ldots, \mu_{n}\right)$ if for all $i: \operatorname{marg}_{A_{-i}}\left[\phi_{i}\left(s_{i}^{\infty}\right)\right]=\otimes_{k \neq i} \mu_{k}=$ $\mu_{1} \otimes \ldots \otimes \mu_{i-1} \otimes i_{i+1} \otimes \ldots \otimes \mu_{n}$.

The main result of this subsection is due to Armbruster and Böge (1979). It says that for two players, if rationality is comnon knowledge, and if each player knows the other piayer, then they play a mixed strategy Nash equilibrium.

Definition 6.3.2: Given an n-tuple $\left(s_{1}^{\infty}, \ldots, s_{n}^{\infty}\right)$ of beliefs, we say trat player $i$ knows the other olayers if: $\operatorname{supp} \operatorname{marg}_{S_{-i}}\left\{\phi_{i}\left(s_{i}^{\infty}\right)\right]=\left\{s_{-i}^{\infty}\right\}$.

This definition simply says that player $i$ thinks that the only possible (n-1)-tuple of beliefs of other players is the actual one:

$s_{-i}^{\infty}=\left(s_{1}^{\infty}, \ldots, s_{i-1}^{\infty}, s_{i+1}^{\infty}, \ldots, s_{n}^{\infty}\right)$.

The following theorem is a characterization of Nash equilibria in tivo-person games. The first part of the theorem below is in Armbruster and Böge (1979).

Theorem 6.3.1: Let $\Gamma$ be a two-person game. Suppose rationality is common knowledge, and that player 1 knows player 2 and player 2 knows player 1 . Then they play a mixed strategy Nash equilibrium of the game $\Gamma$ in the sense of Definition 6.3.1. Conversely, if $\left(\mu_{1}, \mu_{2}\right)$ is a mixed strategy Nash equilibrium of $r$, there are beliefs $\left(s_{1}^{\infty}, s_{2}^{\infty}\right)$ such that rationality is common knowledge, and each player knows each other, with the property that $\left(s_{1}^{\infty}, s_{2}^{\infty}\right)$ plays $\left(\mu_{1}, \mu_{2}\right)$ in the sense of Definition 6.3.1.

Proof: Consider the pair $\mu_{1}=\operatorname{marg}_{A_{1}}\left[\phi_{2}\left(s_{2}^{\infty}\right)\right]$ and $\mu_{2}=\operatorname{marg}_{A_{2}}\left[\phi_{1}\left(s_{1}^{\infty}\right)\right]$. We know that $\forall a_{1} \varepsilon$ supp $\mu_{1}, a_{1}$ is a best response to $\mu_{2}$, since player 2 thinks player 1 is rational, and $\operatorname{marg}_{S_{1}}\left[\phi_{2}\left(s_{2}^{\infty}\right)\right]=\left\{s_{1}^{\infty}\right\}$. Similarly, $\forall a_{2} \varepsilon$ supp $\mu_{2}$, $a_{2}$ is a best response to $\mu_{1}$. Thus $\left(\mu_{1}, \mu_{2}\right)$ is a mixed strategy equilibrium of the game $\Gamma$. Conversely, suppose $\left(\mu_{1}, \mu_{2}\right)$ is a mixed strategy Nash equilibrium of the game $u$. One can construct the infinite hierarchies of beliefs $\left(s_{1}^{\infty}, s_{2}^{\infty}\right)$ 
which will play $\left(\mu_{1}, \mu_{2}\right)$ by rationalizing in each round every point in the support of one of the mixed strategies by the mixed strategies of the opponent. These infinite hierarchies of beliefs will obviously satisfy the requirements of the theorem.

Q.E.D.

This result is appealing in the sense that if two players in a game are so familiar with each other that they know each other's beliefs completely, then if rationality is also comnon knowledge, each player's prior on the other player's strategic choice must be one of the other player's Nash equilibrium mixed strategies in a two-person game. Moreover, the two priors come from the same Nash equilibrium. Each player would then take a strategy in the support of his own equilibrium mixed strategy.

This result seems to lend support to one view of the Nash equilibrium. It is that players are able to discuss the game with each other and formulate beliefs based on this discussion. If sufficient discussion has come to pass, the players should know each other's beliefs. This, along with rationality, leads to Nash equilibrium behavior.

Unfortunately, the result above is not true for games with more than two players. Consider a situation with three players. Each player has beliefs over the actions of the other players. Suppose these beliefs satisfy the following condition: for each player $i$, the support of the beliefs on the actions of player $k(k \neq i)$ is contained in the set of best responses of player $k$ against player $k^{\prime} s$ beliefs over actions of players who are not $k$. If there were only two players, the condition above would imply that the two players were playing a mixed strategy Nash equilibrium, according to definition 6.2.1. With three players, the situation changes. It is not necessarily true that these players have a common prior. Thus, even when all the three players know each other, it is possible that they are not at a liash equilibrium: this because they may hold 
priors about the actions of others which are not consistent wit a common prior. The next example will illustrate this point in formal terms.

Examole 6.3.1: (Common Knowledge of Rationality and Knowledge of Each Other Does Not Imply Nash Behavior in Three-Person Games.) There are three players. The pure strategy sets are: $A_{1}=\{u, d\}, A_{2}=\{a, b\}$ and $A_{3}=\{L, R\}$. The payoffs are given by the two matrices below. The matrix on the left corresponds to player three playing L. The matrix on the right $R$.

Figure 1 here

Define $\mu_{i j} \in \Delta\left(A_{j}\right)$, for $i \neq j$, and $i, j=1,2,3$, by:

$\mu_{12}=(1 / 2 \mathrm{a}, 1 / 2 \mathrm{~b}), \quad \mu_{13}=(1 / 2 \mathrm{~L}, 1 / 2 \mathrm{R})$;

$\mu_{21}=(1 / 3 u, 2 / 3 d), \quad \mu_{23}=(1 / 3 L, 2 / 3 R) ;$

$\mu_{31}=(2 / 3 u, 1 / 3 d), \quad \mu_{3}=(2 / 3 a, 1 / 3 b)$.

Then, we have:

$A_{1}=$ set of best responses to $\mu_{12} \otimes \mu_{13}=v_{1}$;

$A_{2}=$ set of best responses to $\mu_{21} \otimes \mu_{23}=v_{2}$ i

$A_{3}=$ set of best responses to $\mu_{32} \mu_{31}=v_{3}$. 
We now construct three infinite hierarchies of beliefs $\left(s_{1}^{\infty}, s_{2}^{\infty}, s_{3}^{\infty}\right)$ such that for every $i: \operatorname{marg}_{A_{j} \times A_{k}}\left[\Phi_{i}\left(s_{i}^{\infty}\right)\right]=\mu_{i j} \mu_{i k}$ for $j, k \neq i$, with $j \neq k$. These hierarchies of beliefs will be such that rationality is common knowledge and for all i: supp marg $\sin _{i} \times S_{k}\left[\phi_{i}\left(s_{i}^{\infty}\right)\right]=\left\{\left(s_{i}^{\infty}, s_{k}^{\infty}\right)\right\}$ for $j \neq k$, and $j, k \neq i$ (this means that each player knows the other two players). The construction is simultaneous. The first order beliefs, $s_{1}^{1}, s_{2}^{1}, s_{3}^{1}$ are given by $v_{1}, v_{2}, v_{3}$, respectively. The higher order beliefs will be all constructed in the same fashion as the second order beliefs. For example, $s_{1}^{2} \varepsilon \Delta\left(A_{2} \times A_{3} \times s_{2}^{1} \times S_{3}^{1}\right)$ is given by: $s_{21}=s_{11} \delta\left\{\left(s_{2}^{1}, s_{3}^{1}\right)\right\}$, where $\delta\{\cdot\}$ is the probability measure which puts mass 1 on the set $\{\cdot\}$. The hierarchies of beliefs thus built are clearly consistent and satisfy the properties required above. However, $\mu_{21} \neq \mu_{31}$, $\mu_{12} \neq \mu_{32}, \quad \mu_{13} \neq \mu_{23}$. Therefore the triple $\left(s_{1}^{\infty}, s_{2}^{\infty}, s_{3}^{\infty}\right)$ does not play a mixed strategy Nash equilibrium.

6.4. THE EXCHANGEABILITY AXIOM AND THE NASH HYPOTHESIS

A final axiom we study in relation to Nash behavior is exchangeability. Although it is less intuitive than the earlier assumptions, it is weaker and the first result we obtain requires no knowledge of Nash theory as in contrast to the earlier sections. It is therefore somewhat appealing since it derives Nash behavior from more basic assumptions. However, exchangeability itself is a strong assumption.

Hence, Theorem 6.4 .1 below states that in a two-player game, if two basic assumptions on beliefs are imposed on a player, then as long as his beliefs satisfy these conditions, his introspection will lead him to believe that his opponent will play a Nash equilibrium (in the sense of Definition 6.3 .1 -- that 
his prior on the opponent's strategy is one of his opponent's equilibrium mixed strategies). Then he himself will take an action in the support of his own equilibrium mixed strategy.

Axiom [E]: Exchangeability is common knowledge among players:

$\forall i: \quad s_{i}^{\infty} \varepsilon \underset{\ell \geq 1}{n} E_{i}^{\ell}, \cdot$

where $\forall i, \ell$ :

$E_{i}^{1}=\left\{s_{i}^{\infty} \varepsilon S_{i}^{\infty} ; \forall j \operatorname{supp} \operatorname{marg}\left(A_{j} x S_{j}^{\infty}\right)\left[\phi_{i}\left(s_{i}^{\infty}\right)\right]=C_{j} \times D_{j}\right.$ for some $C_{j} \subset A_{j}$ and $\left.D_{j} \subset S_{j}^{\infty}\right\}$

$\ell \geq 2: E_{i}^{\ell}=\left\{s_{i}^{\infty} \varepsilon E_{i}^{\ell-1} ; \forall j, s_{j}^{\infty} \varepsilon \operatorname{supp} \operatorname{marg}_{s_{j}^{\infty}}\left[\phi_{i}\left(s_{i}^{\infty}\right)\right] \Rightarrow s_{j}^{\infty} \varepsilon E_{j}^{\ell-1}\right\}$.

[In words: the exchangeability hypothesis being common knowledge simply means that it is common knowledge among players that if an action by player $j$, $a_{j} \varepsilon A_{j}$, is considered possible by player $i$, then he also considers it possible when player $j$ is of any of the types $s_{j}^{\infty}$ he believes player $f$ can be.]

Certain games have rationalizable strategies which are rationalized by a player $i$ believing that player $j$ is persistently wrong about himself (i). We require another restriction on beliefs to eliminate these completely inconsistent beliefs. The following assumption requires that $i$ believes $j$ may be correct about i:

Definition 6.4.2: Player $i$ is said to be conjecturally consistent if:

$\forall j \neq i: \forall s_{j}^{\infty} \varepsilon \operatorname{supp} \operatorname{marg} s_{j}^{\infty}\left[\phi_{i}\left(s_{i}^{\infty}\right)\right] \Rightarrow s_{i}^{\infty} \varepsilon \operatorname{supp} \operatorname{marg} s_{i}^{\infty}\left[\phi_{j}\left(s_{j}^{\infty}\right)\right] \ldots$

Before proving the main theorem of this section, we will reinterpret the notion of Nash equilibrium in a two person game. Let us suppose $\left(\mu_{1}, \mu_{2}\right)$ is a Nash equilibrium of $\Gamma$ in mixed strategies. We can interpret these as beliefs 
about other players' actions, so that $\mu_{1} \varepsilon \Delta\left(A_{1}\right)$ is the belief that player 2 has about player one's actions. He will then choose $a_{2} \varepsilon$ supp $\mu_{2}$. Conversely, $H_{2} \varepsilon \Delta\left(A_{2}\right)$ is the belief that player 1 has about 2 's actions. By the same token player 1 will choose $a_{1} \varepsilon$ supp $\mu_{1}$ (this by definition of Nash equilibrium: any action in the support of the Nash mixed strategy must be a best response against the mixed strategy of the other player).

Theorem 6.4.1: Suppose player i satisfies Axioms [B], [B.R], [R] and [E]. Let player $i$ be conjecturally consistent. Also let $\Gamma$ be a two person game. Then, for $j \neq i, \operatorname{marg}_{A_{j}}\left[\phi_{i}\left(s_{i}^{\infty}\right)\right]$ is a Nash equilibrium mixed strategy for player $j$. (This means that player $i$ thinks player $j$ is behaving according to a Nash mixed strategy, and, since player $i$ is rational, he will choose an action in the support of his mixed strategy Nash response.)

Proof: Let us fix $i=1$, without loss of generality. Then, if $a_{2} \varepsilon$ supp $\operatorname{marg}_{A_{2}}\left[\phi_{1}\left(s_{1}^{\infty}\right)\right]$, we must have, by the fact that $s_{1}^{\infty} \varepsilon K_{1}^{\infty} \cap E_{1}^{\infty}$, that $a_{2}$ is a best response against $\operatorname{marg}_{A_{1}}\left[\phi_{2}\left(s_{2}^{\infty}\right)\right]$, for every $s_{2}^{\infty} \varepsilon$ supp marg $s_{2}^{\infty}\left[\phi_{1}\left(s_{1}^{\infty}\right)\right]$. But by conjectural consistency we have $s_{1}^{\infty} \varepsilon \operatorname{supp} \underset{S_{1}^{\infty}}{\operatorname{marg}}\left[\phi_{2}\left(s_{2}^{\infty}\right)\right]$. As player 1 thinks player 2 thinks he is rational $\left(s_{1}^{\infty} \varepsilon K_{1}^{2}\right)$, we must have that $\left(a_{1}, s_{1}^{\infty}\right) \varepsilon \operatorname{supp}\left[\phi_{2}\left(s_{2}^{\infty}\right)\right]$, then $a_{1}$ is a best response to $\operatorname{marg}_{A_{2}}\left[\phi_{1}\left(s_{1}^{\infty}\right)\right]$. By exchangeability this must be true for every $a_{1} \varepsilon \operatorname{supp} \operatorname{marg}_{A_{1}}\left[\phi_{2}\left(s_{2}^{\infty}\right)\right]$. Consider the pair: $\mu_{1}=\operatorname{marg}_{A_{1}}\left[\phi_{2}\left(s_{2}^{\infty}\right)\right]$ for any $s_{2}^{\infty} \varepsilon \operatorname{marg} \operatorname{supp} S_{2}^{\infty}\left[\phi_{1}\left(s_{1}^{\infty}\right)\right]$, and $\mu_{2}=\operatorname{marg}_{A_{2}}\left[\phi_{1}\left(s_{1}^{\infty}\right)\right]$. Then they form a Nash equilibrium, because: $\forall a_{1} \varepsilon \operatorname{supp} \mu_{1}, a_{1}$ is the best response against $\mu_{2}$, 
and $\forall a_{2} \varepsilon$ supp $\mu_{2}, a_{2}$ is the response against $\mu_{1}$. Notice that we used in the proof only that $s_{i}^{\infty} \in E_{i}^{2} \cap K_{i}^{2}$.

This result cannot be generalized to $n$-person games unfortunately. See Werlang (1986) for an example.

We now use exchangeability to generalize some of the earlier results (in particular Theorems 6.1.1 and Proposition 6.2.1). Instead of requiring the Nash theory to be common knowledge we replace it with exchangeability being common knowledge. In addition, we need the fact that the players may know who the other players are:

Definition 6.4.3: An n-tuple of players beliefs $\left(s_{1}^{\infty}, \ldots, s_{n}^{\infty}\right)$ is said to satisfy direct consistency when for all $i, s_{-i}^{\infty} \in \operatorname{supp} \underset{s_{-i}^{\infty}}{\operatorname{marg}}\left[\phi_{i}^{\infty}\left(s_{i}^{\infty}\right)\right]$.

With these two hypotheses we have, then:

Theorem 6.4.2: Let $r$ be a two-person game. Suppose $\left(s_{1}^{\infty}, s_{2}^{\infty}\right)$ are such that: (i) $s_{i} \in K_{i}^{1} \cap E_{i}^{1}$ for $i=1,2$; and (ii) $\left(s_{1}^{\infty}, s_{2}^{\infty}\right)$ are directly consistent. Then $\left(s_{1}^{\infty}, s_{2}^{\infty}\right)$ plays a Nash equilibrium. Conversely, any Nash equilibrium can be played by beliefs which obey (i) and (ii).

Proof. Let $a_{2} \varepsilon$ supp $\operatorname{marg}_{A_{2}}\left(\phi_{1}\left(s_{1}^{\infty}\right)\right]$. By $s_{1}^{\infty} \varepsilon K_{i}^{1} \cap E_{i}^{1}$, $a_{2}$ is a best response to belief $s_{2}^{\infty}$. So that $a_{2}$ is best response to $\operatorname{marg} A_{2}\left[\phi_{1}\left(s_{1}^{\infty}\right)\right]$. In the same way, $a_{1} \varepsilon$ supp marg $A_{1}\left[\phi_{2}\left(s_{2}^{\infty}\right)\right]$ implies $a_{1}$ is a best response to $\operatorname{marg}_{A_{1}}\left[\phi_{2}\left(s_{2}^{\infty}\right)\right]$. Thus, $\left(\mu_{1}, \mu_{2}\right)$ given by $\left(\operatorname{marg}_{A_{1}}\left[\phi_{2}\left(s_{2}^{\infty}\right)\right], \operatorname{marg}_{A_{2}}\left[\phi_{1}\left(s_{1}^{\infty}\right)\right]\right)$ is a Nash equilibrium. Hence, $\left(s_{1}^{\infty}, s_{2}^{\infty}\right)$ plays the mixed strategy Nash equilibrium 
$\left(\mu_{1}, \mu_{2}\right)$. The converse follows from the converse of Theorem 6.3.3.

Q.E.D.

We can also generalize Proposition 6.2.1 when applied to strictly concave games. This involves the exchangeability hypothesis, as well as a plausible assumption: the assumption that each player thinks that the other players may think that a Nash equilibrium is being played.

Theorem 6.4.3: Let $s_{i}^{\infty} \varepsilon K_{i}^{1} \cap E_{i}^{2}$. Suppose $\Gamma$ is a game where $\left(\tilde{a}_{1}, \ldots, \tilde{a}_{n}\right)$ is a Nash equilibrium such that every action $\tilde{a}_{j}$ is the unique best response against $\tilde{a}_{-j}$ (in particular any strictly concave game will do). Assume that $s_{i}$ is an element of the set $\left\{s_{i}^{\infty} \in S_{i}^{\infty} \mid \forall K \neq i\right.$ : there exists $s_{k}^{\infty} \varepsilon$ supp marg $S_{k}^{\infty}\left[\phi_{i}\left(s_{i}^{\infty}\right)\right]$, such that $\left.\operatorname{marg}_{A_{-k}}\left[\phi_{k}\left(s_{k}^{\infty}\right)\right]=\delta_{\left\{\tilde{a}_{-k}\right.}\right\}^{\cdot}$ Then if player $i$ is rational, he will choose $\tilde{a}_{i}$, the Nash action. Notice that uniqueness of Nash equilibria is not required. Conversely, any Nash equilibrium with the properties above may be played by hierarchies of beliefs with the properties above.

Proof. Since there exists $s_{k}^{\infty} \varepsilon$ supp $\underset{s_{k}^{\infty}}{\operatorname{marg}}\left(\phi_{i}\left(s_{i}^{\infty}\right)\right]$, such that $\left.\operatorname{marg}_{A_{-k}}\left[\phi_{k}\left(s_{k}^{\infty}\right)\right]=\delta \tilde{a}_{-k}\right\}$ and since $\tilde{a}_{k}$ is unique best response to $\tilde{a}_{-k}$ then supp $\operatorname{marg}_{A_{k}}\left[\phi_{i}\left(s_{i}^{\infty}\right)\right]=\left\{\tilde{a}_{k}\right\}$ by $k_{i}^{1}$ and $E_{i}^{2}$. But player $i$ is rational, and again, $\tilde{a}_{i}$ is unique best response to $\tilde{a}_{-i}$, so that player $i$ chooses $\tilde{a}_{i}$. The converse of the theorem is a direct consequence of the converse of Theorem 6.1 .1

Q.E.D.

It is interesting to note that there are several instances where Nash equilibria are played (in the sense of Definition 6.3.1) in which the exchangeability hypothesis is necessary. To see that, suppose $\left(s_{1}^{\infty}, \ldots, s_{n}^{\infty}\right)$ are types of 
an $n$-person game $r$. Assume that $\left(\mu_{1}, \ldots, \mu_{n}\right)$ is a mixed strategy Nash equilibrium of the; game $u$, and that $\left(s_{1}^{\infty}, \ldots, s_{n}^{\infty}\right)$ plays $\left(\mu_{1}, \ldots, \mu_{n}\right)$ in the sense of Definition 6.3.1, that is to say: for all $i \operatorname{marg}_{A}\left[\phi_{i}\left(s_{i}^{\infty}\right)\right]=\otimes_{k \neq i} \mu_{k}$. Two hypotheses will imply the necessity of exchangeability. The first hypothesis assumes that every $t_{k}^{\infty} \varepsilon$ supp $\operatorname{marg}_{S_{k}}\left[\phi_{i}\left(s_{i}^{\infty}\right)\right]$ is such that $t_{k}^{\infty}$ thinks the Nash equilibrium $\left(\mu_{1}, \ldots, \mu_{n}\right)$ is played. This hypothesis requires very little Justification: it is very unlike Nash equilibrium to suppose it is being played without supposing other people think so also. To contradict it would be the same as saying that the players got to the Nash point by mere coincidence, which sounds extremely odd. The other assumption is less intuitive. It is a principle of a priori ignorance. Given a belief $t_{k}^{\infty}$ is considered possible by player $i$, any $a_{k}$ which is a best response to $t_{k}^{\infty}$ must be considered possible of being played by $t_{k}^{\infty}$, in the eyes of player $i$. Notice that we do not require player i to consider all best responses equally likely. We only need player i to consider that all actions which are best responses for $t_{k}^{\mathbf{m}}$ are possible of being played by $t_{k}^{\infty}$. We conclude this section by stating the "necessity" of the exchangeability hypothesis:

Theorem 6.4.4: Suppose $\left(s_{1}^{\infty}, \ldots, s_{n}^{\infty}\right)$ is such that they play the mixed strategy Nash equilibrium $\left(\mu_{1}, \ldots, \mu_{n}\right)$. Assume that the players think that other players think this Nash equilibrium is played. Finally, suppose that the ignorance principle holds, that is to say: $\forall i, \forall k \neq i: t_{k}^{\infty} \varepsilon \operatorname{supp} \operatorname{marg}_{S_{k}}\left[\phi_{i}\left(s_{i}^{\infty}\right)\right]$, and if $a_{k}$ is a best response to $\operatorname{marg}_{A_{-k}}\left[\phi_{k}\left(t_{k}^{\infty}\right)\right]$ then $\left(a_{k}, t_{k}^{\infty}\right) \varepsilon$ supp marg ${ }_{A_{k} \times S_{k}^{\infty}}\left[\phi_{i}\left(s_{i}^{\infty}\right)\right]$. Then: $\forall i: s_{i}^{\infty} \in E_{i}^{1}$.

Proof: Immediate from the definitions above. Q.E.D. 


\section{CORRELATED EQUILIBRIUM AND COMMON PRIORS -- A RESULT OF AUMANN}

Aumann (1985) examines the concept of correlated equilibrium in very much the same spirit as our analysis of iterated dominance. He shows that rationality and a common prior being common knowledge gives rise to a correlated equilibrium. We provide that result in our framework below.

It should be noticed that the common prior assumption is stronger than the earlier axioms we have examined. It requires the highest degree of coordination among the solution concepts. It requires, implicitly, that players discuss the game before they play (as in some of the Nash justifications). Moreover, they set up a randomization device to correiate their actions. When it comes time to actually play the game, they believe that their earlier discussion was valid and their beliefs come from the common prior of the randomization device. Hence the degree of centralization and coordination in a correlated equilibrium is the highest of the solution concepts we have examined.

First, we must amend the definition of the infinite recursion of beliefs for player i to conform with the spirit of Aumann (1985). There, player i's basic domain of uncertainty includes his own strategies as well. This is in keeping with the interpretation that the randomization device the players have set up before the game will tell player i which strategy to take (very much like a traffic light).

By abuse of notation in this section, we let $s_{i}^{0}=\prod_{i=1}^{n} A_{i}$ and $s_{i}^{l}=\Delta\left(\underset{j=1}{n} A_{i} \times \underset{j \neq i}{I} S_{j}^{l-1}\right), S_{i}^{\infty}$ is appropriately changed as well. So that there is a canonical homeomorphism, $\phi_{i}: s_{i}^{\infty}+\Delta\left(\underset{j=1}{n} A_{j} \times \underset{j \neq i}{\operatorname{II}} s_{j}^{\infty}\right)$. Hence; a belief of player $i$ in this section provides a prior on the strategies of all the players, including his own, and the beliefs of the other players. 
Definition 7.1: A Correlated Equilibrium is given by $P \in \Delta\left(\underset{j=1}{n} A_{j}\right)$, a regular probability measure, with well defined conditional probability measures given each $a_{i}$ such that for every $a_{i} \in \operatorname{supp} \operatorname{marg}_{A_{i}} P$,

$$
a_{i} \varepsilon \underset{\hat{a}_{i} \in A_{i}}{\arg } \max _{-i} \bar{U}\left(\hat{a}_{i}, a_{-i}\right) d P\left(a_{-i} \mid a_{i}\right)
$$

The interpretation of this definition (which by Aumann (1984) is equivalent to other formulations) is that the realization of the randomizing device tells player $i$ to play $a_{i}$. The probability distribution of the randomization is $P$. Hence, given the recommendation $a_{i}$, player i's conditional distribution on the strategies of the other players (what the device recommended to the other players) is $P\left(\cdot \mid a_{i}\right)$. Hence if $P$ is a correlated equilibrium, it must be the case that $a_{i}$ is a best response to the conditional distribution $P\left(\cdot \mid a_{i}\right)$.

Definition 7.2: We say that player i's beliefs come from a prior $P \in \Delta\left(\mathbb{J}_{j=1}^{n} A_{j}\right)$ if $s_{i}^{\infty} \varepsilon C P_{i}^{0}=\left\{s_{i}^{\infty} \varepsilon s_{i}^{\infty}\right.$ : there exists $a_{i} \varepsilon$ supp marg ${ }_{A_{i}} P$ such that

(i) supp $\operatorname{marg}_{A_{i}}\left[\phi_{i}\left(s_{i}^{\infty}\right)\right]=\left\{a_{i}\right\}$

(ii) $\left.\operatorname{marg}_{A-i}\left[\phi_{i}\left(s_{i}^{\infty}\right)\right]=P\left(\cdot \mid a_{i}\right)\right\}$

Player $i$ believes that the other player's beliefs come from the common prior $P$ if:

$$
\begin{aligned}
& s_{i}^{\infty} \varepsilon C P_{i}^{l}=\left\{s_{i}^{\infty} \in s_{i}^{\infty}: \forall j \neq i, \forall\left(a_{j}, s_{j}^{\infty}\right) \varepsilon \operatorname{supp} \operatorname{marg} A_{j} \times s_{j}^{\infty}\left[\phi_{i}\left(s_{i}^{\infty}\right)\right],\right. \\
& \left.\operatorname{marg}_{A_{-j}}\left[\phi_{j}\left(s_{j}^{\infty}\right)\right]=P\left(\cdot \mid a_{j}\right)\right\} .
\end{aligned}
$$


For $\ell \geq 2$,

$$
C P_{i}^{\ell}=\left\{s_{i}^{\infty} \in C P_{i}^{l-1}: \forall j \neq i, \forall s_{j}^{\infty} \varepsilon \text { supp inarg } \underset{s_{j}^{\infty}}{ }\left[\phi_{i}\left(s_{i}^{\infty}\right)\right], s_{j}^{\infty} \in C P_{j}^{l-1}\right\}
$$

By constructing the beliefs of player $i$, one can show that for any $a_{i}$ $\varepsilon$ supp $\operatorname{marg}_{A_{i}} P$, there is $s_{i}^{\infty} \in \underset{l \geq 0}{n} C P_{i}^{\ell}$ such that $\operatorname{supp} \operatorname{marg}_{A_{i}}\left[\phi_{i}\left(s_{i}^{\infty}\right)\right]=\left\{a_{i}\right\}$. In particular, for any $i$, it can be shown that

$$
\left.s_{i}^{\infty} \sum_{\ell \geq 0}^{u} \operatorname{CP}_{i}^{\ell} \operatorname{supp}^{\operatorname{sarg}} A_{i} \mid \phi_{i}\left(s_{i}^{\infty}\right)\right]=\operatorname{supp} \operatorname{marg}_{A_{i}} P
$$

Axiom [CP]: The common prior $P \in \Delta\left(\prod_{j=1}^{n} A_{j}\right)$ is common knowledge: $\forall i, s_{i}^{\infty} \varepsilon \underset{\ell \geq 0}{n} \mathrm{CP}_{i}^{l}$

Theorem 7.1 (Aumann): Suppose Axioms [B] and [BR] hold. Moreover, assume that there is $P \in \Delta\left(\underset{j=1}{\prod_{j} A_{j}}\right)$ such that for every $i, s_{i}^{\infty} \varepsilon \sum_{\ell=0}^{2} C P_{i}^{\ell}$. Moreover, for any $\left(s_{1}^{\infty} ; \ldots, s_{n}^{\infty}\right) \varepsilon \prod_{j=1}^{n}\left({ }_{\ell=0}^{2} C P_{j}^{\ell}\right)$, Axiom [R] is satisfied. Then, $P$ is a correlated equilibrium.

Proof: We need to show that $\forall i, \forall a_{i} \in \operatorname{supp}^{\text {marg }} \mathrm{A}_{i} P$,

$$
a_{i} \varepsilon \underset{a_{i} \varepsilon A_{i}}{\arg \max } V\left(\hat{a}_{i}, P\left(\cdot \mid a_{i}\right)\right)
$$

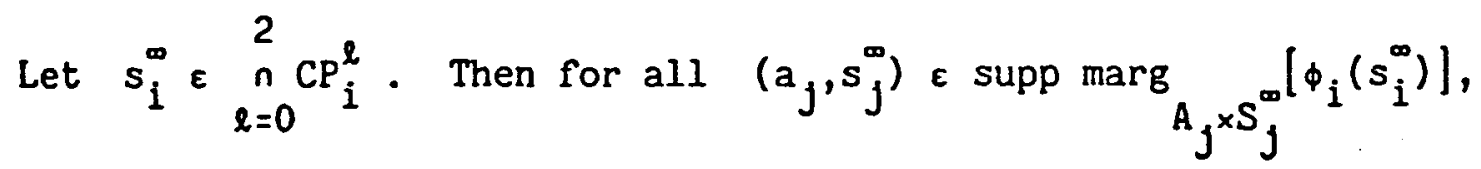

$$
\operatorname{marg}_{A_{-j}}\left[\phi_{j}\left(s_{j}^{\infty}\right)\right]=P\left(\cdot \mid a_{j}\right) \text { since } s_{i}^{\infty} \varepsilon C P_{i}^{1}
$$




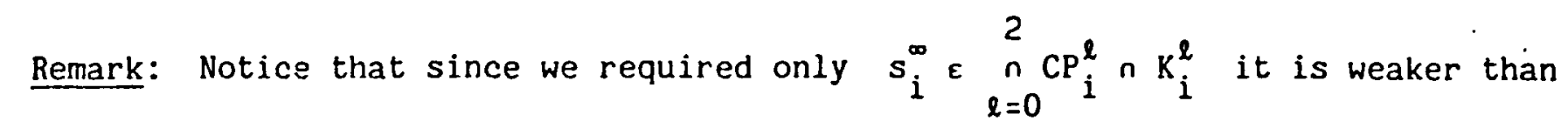
requiring that the prior $P$ and rationality being common knowledge. In Aumann (1985), the model implicitly had.common knowledge of rationality and the prior built in at every state of the world.

This theorem is really another version of Theorem 6.1.1 in disguise. Correlated equilibria are Nash equilibria of a game with an expanded strategy space.

Aumann (1985) discusses the concept of subjective correlated equilibrium. This is the case where players are permitted to have different priors and may believe that other players have different priors. This is, by Theorem 5.2, the same as the iteratively undominated strategies. 


\section{CONCLUSION}

We developed a Bayesian framework for the analysis of normal form games and demonstrated how different sets of axioms or assumptions on the priors of the players in a game results in different behavior.

We applied the framework to four solution concepts. Our own interpretation of the results is that the degree of coordination and communication which occurred before the game is played is crucial in guiding us to choose the appropriate solution concept.

Thus if none such were thought possible before the game, the appropriate concept has to be rationalizable or iteratively undominated strategies. Here, our own subjective feeling is that although iteratively undominated strategies requires less assumptions than rationalizable, it is more peculiar because each player is acting independently from other players, yet he permits other players to correlate.

Nash equilibrium was examined in detail and we provided formalizations of traditional justifications as well as new results. Although we derived conditions under which introspection alone would result in a Nash equilibrium in a two-person game, these results do not generalize. Hence, for more general games, the traditional justification, which in our opinion requires the players to communicate and agree on a Nash equilibrium point, must be appealed to. Consequently, we feel that a Nash equilibrium is appropriate for situations in which the players in a game have either a large degree of commonality (in particular, their beliefs about each other are not too far wrong in the several senses analyzed in Section 6) or that they have the opportunity to agree on a self-enforcing contract.

Finally, correlated equilibria require the additional assumption of correlation with a common prior. We feel that this solution concept requires the 
greatest degree of coordination. The players must not only agree to an equilibrium as in Nash, they must set-up a randomization mechanism before the game is played in order to correlate their behavior.

If communication and coordination underlies both the Nash and correlated equilibria, and if an analyst is willing to permit such activities in the situation he is studying, it seems natural then to eliminate equilibria which are pareto dominated by other equilibria. This is a suggested axiom which seems natural if one is willing to assume such a high degree of coordination as is implicit in these two solution concepts. 


\section{References}

1. Abreu and D. Pearce, On the Inconsistency of Certain Axioms on Solution Concepts for Non-Cooperative Games, J. Econ. Theory 34 (1984), 169-174.

2. W. Armbruster and W. Böge, Bayesian Game Theory, in "Game Theory and Related Topics," (0. Moeschlin and D. Pallaschke, Ed.), North-Holland Press, Amsterdam, 1979.

3. R.J. Aumann, Subjectivity and Correlation in Randomized Strategies, J. Math. Econ. $1(1974), 67-96$.

4. R.J. Aumann, Agreeing to Disagree, Ann. Statist. 4 (1976), 1236-1239.

5. R.J. Aumann, Correlated Equilibrium as an Expression of Bayesian Rationality, discussion paper, 1985.

6. J. Banks and J. Sobel, Equilibrium Selection in Signalling Games, discussion paper 85-9, University of California, San Diego, 1985.

7. B.D. Bernheim, Rationalizable Strategic Behavior, Econometrica 52 (1984), $1007-1028$.

8. B.D. Bernheim, Axiomatic Characterization of Rational Choice in Strategic Environments, Revised Version, discussion paper, 1985.

9. P. Billingsley, "Convergence of Probability Measures," John Wiley \& Sons, New York, 1968.

10. K. Binmore, Modelling Rational Players, Revised Version, Caress Working Paper, 85-36, University of Pennsylvania, 1985.

11. W. Böge, W. and T.H. Eisele, On Solutions of Bayesian Games, Int. J. Game Theory $8(1979), 193-215$.

12. A. Brandenburger and E. Dekel, Rationalizability and Correlated Equilibria, discussion paper, Stanford University, 1985.

13.. J. Farrell, Credible Neologisms in Games of Communication, discussion paper, Massachusetts Institute of Technology, 1984. 
14. S. Grossman and M. Perry, Sequential Bargaining under Asymmetric Information, Foerder Institute Working Paper 33-84, 1984.

15. J.C. Harsanyi, Games with Incomplete Information Played by "Bayesian" Players, Part I-III, Management Sci. 14 (1967-68), 159-182, 320-334, 486502 .

16. H. Hildenbrand, "Core and Equilibria of a Large Economy," Princeton University Press, Princeton, 1984.

17. J.L. Kelley and I. Namioka, "Linear Topological Spaces," Springer-Verlag, New York-Heidelberg-Berlin, 1963.

18. E. Kohlberg, Lecture at 1981 N.B.E.R. Conference on Mathematical Economics, University of California, Berkeley, 1981 :

19. E. Kohlberg and J.F. Mertens, On the Strategic Stability of Equilibria, C.O.R.E. discussion paper 8284, 1982.

20. D. Kreps and R. Wilson, Sequential Equilibria, Econometrica 50 (1982), 86394.

21. D. Kreps, Signalling Games and Stable Equilibria, discussion paper, Stanford University, 1985.

22. D. Luce and H. Raiffa, "Games and Decisions," John Wiley \& Sons, New York, 1957.

23. A. McLennan, Justifiable Beliefs in Sequential Equilibrium, Econometrica 53, in press.

24. J.F. Mertens and S. Zamir, Eormalization of Harsanyi's Notion of 'Type' and 'Consistency' in Games with Incomplete Information, C.O.R.E. discussion paper, Universite Catholique de Louvain, 1982.

25. P. Milgrom and R. Weber, Topologies on Information and Related Strategies in Games With Incomplete Information, in "Game Theory and Topics" (0. Moeschlin and D. Pallaschke., Eds.), North-Holland, Amsterdam, 1979. 
26. H. Moulin, Dominance Solvable Voting Schemes, Econometrica 47 (1979), 133751.

27. R. Myerson, Refinement of the Nash Equilibrium Concept, Int. J. Game Theory I (1978), 73-80.

28. R. Myerson, Bayesian Equilibrium and Incentive Compatibility: An Introduction," J.L. Kellogg Graduate School of Management, discussion paper No. 548 , Northwestern University, 1983:

29. R. Myerson, Private Communication, 1984.

30. D. Pearce, Rationalizable Strategic Behavior and the Problem of Perfection, Econometrica $52(1984), 1029-1050$.

31. M. Reed and B. Simon, "Methods of Modern Mathematical Physics, I: Functional Analysis," Academic Press, New York, 1980.

32. P. Reny, Rationality, Common Knowledge and the Theory of Games, discussion paper, Princeton University, 1985.

33. L.J. Savage, "The Foundations of Statistics," John Wiley \& Sons, New York, 1954.

34. R. Selten, Spieltheoretische Behandlung eines Oligopolmodells mit Nachfragetragheit; Zeitschrift fur die gesante Staatsurssenschaft 12 (1965), $301-324$.

35. R. Selten, A Reexamination of the Perfectness Concept for Equilibrium Points in Extensive Games, Int. J. Game Theory, 4 (1975), 25-55.

36. T. Tan and S.R.C. Werlang, On Aumann's Notion of 'Common Knowledge' -- An Alternative Approach, Working Paper Series in Economics and Econometrics, \#5-26, University of Chicago, 1984.

37. S.R.C. Werlang, "Common Knowledge and Game Theory," Ph.D. thesis, Princeton University, 1986. 


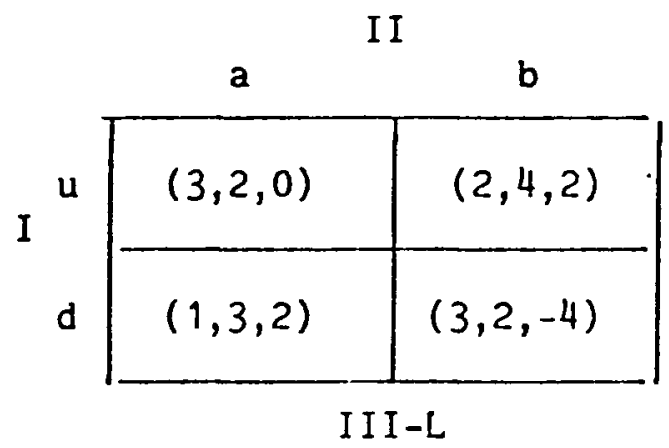

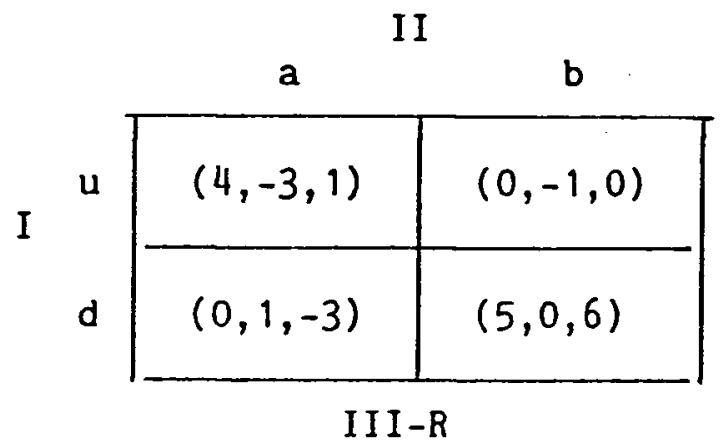

Eigure 1 


\section{APPENDIX A}

In the definition of $S_{i}^{l}$ one could include correlation among all the previous layers of beliefs. This is the approach followed by Mertens and Zamir (1982), but given the consistency requirements they have (as we do below), they show this is equivalent to the framework we use here.

Observe that an arbitrary $\&$-th order belief contains information about all beliefs of order less than $\ell$. An obvious requirement that should hold is that the first order beliefs of player i should be the marginal of his second order belief on his basic uncertainty. We will construct a way of determining the lower order beliefs, given a belief of a certain order. This is the approach of Myerson $(1983,1984)$ : However as it is very enlightening, we think it is worth going through it. Let us impose on a player's beliefs the minimal consistency requirement: that if it is possible to evaluate the probability of an event through his $\ell$-th order beliefs and his $k$-th order beliefs, with $\ell=k$, then both the probabilities agree. Define inductively the functions that will recover the $\ell-1-$ th order beliefs, given $\ell$-th order beliefs, by:

$\ell \geq 2: \Psi_{i}^{\ell-1}: s_{i}^{\ell}+S_{i}^{\ell-1}:$ If $\ell=2, \psi_{i}^{1}\left(s_{i}^{2}\right)(E)=s_{i}^{2}\left(E \times s_{-i}^{1}\right) \forall E \subset s_{i}^{0}$. For $\ell \geq 3$, by induction on $\ell$ we assume $\left(y_{j}^{\ell-2}\right)_{j=1}^{n}$ defined, and:

$\ell \geq 3, \quad \psi_{i}^{\ell-1}\left(s_{i}^{\ell}\right)(E)=s_{i}^{\ell}\left(\left\{\left(s_{i}^{0},\left(s_{j}^{\ell-1}\right){ }_{j=i}\right) \varepsilon s_{i}^{0} \times s_{-i}^{l-1}\right.\right.$

$\left.\left.\left(s_{i}^{0},\left(\Psi_{j}^{\ell-2}\left(s_{j}^{\ell-1}\right)\right)_{j \neq i}\right) \in E\right\}\right), \forall E \subset s_{i}^{0} \times s_{-i}^{l-2}$

We have then:

Proposition A.1: Suppose all players are aware that each of them satisfy the minimum consistency requirement. Then $\forall i, \forall \ell \geq 2: \Psi_{i}^{\ell-1}\left(s_{i}^{\ell}\right)=s_{i}^{2-1}$. 
Proof: Let us prove by induction. For $\ell=2$, let $E \subset s_{i}^{0}$. Then the event $E$ (event $=$ measurable set) is evaluated by $s_{i}^{1}$ as $s_{i}^{1}(E)$. However $E$ is the same as $E \times S_{-i}^{1}$ evaluated by $s_{i}^{2}$. Therefore by the consistency of the players: $s_{i}^{1}(E)=s_{i}^{2}\left(E \times s_{-i}^{1}\right)=\psi_{i}^{1}\left(s_{i}^{2}\right)$. They also know $s_{j}^{1}=q_{j}^{1}\left(s_{j}^{2}\right)$, because they know the others are consistent. Let us assume it is true for $\ell \geq 2$. We will prove that it is true for $\ell+1$. If it is true for $\ell$, we know that $\forall j=1, \ldots, n \quad s_{j}^{\ell-1}=\Psi_{j}^{\ell-1}\left(s_{j}^{\ell}\right)$. Given the event $E \subset s_{i}^{0} \times s_{-i}^{\ell-1}$, define $E^{*} \subset s_{i}^{0} \times s_{-i}^{l}$ by:

$$
E^{*}=\left\{\left(s_{i}^{0},\left(s_{j}^{\ell}\right)_{j \neq i}\right) \varepsilon s_{i}^{0} \times s_{-i}^{\ell} ;\left(s_{i}^{0},\left(w_{j}^{\ell-1}\left(s_{j}^{\ell}\right)\right){ }_{j \neq i}\right) \varepsilon E\right\} .
$$

By the induction hypothesis we have that

$$
E^{*}=\left\{\left(s_{i}^{0},\left(s_{j}^{l}\right)_{j \neq i}\right) \varepsilon s_{i}^{0} \times s_{-i}^{l} ;\left(s_{i}^{0},\left(s_{j}^{l-1}\right)_{j \neq 1}\right) \varepsilon E\right\} .
$$

Therefore $E^{*}$ and $E$ are the "same" events (same in the sense used before: one is true if and only if the other is). Hence by the hypothesis $s_{i}^{\ell}(E)=s_{i}^{\ell+1}\left(E^{*}\right)$. But $\Psi_{i}^{\ell}\left(s_{i}^{\ell+1}\right)(E)=s_{i}^{\ell+1}\left(E^{*}\right)$, and so the result follows.

Q.E.D.

Given the proposition above, we will restrict ourselves to consistent beliefs. Therefore the set of all possible beliefs for player $i$ is:

$$
s_{i}^{\infty}=\left\{\left(s_{1}^{1}, s_{i}^{2}, \ldots\right) \varepsilon \mathbb{I I}_{\ell \geq 1} s_{i}^{l} ; \forall \ell: \psi_{i}^{l}\left(s_{i}^{l+1}\right)=s_{i}^{l}\right\} .
$$




\section{APPENDIX B}

We prove several technical lemmata regarding the measurability of beliefs which rationalize strategies. These results are of interest in themselves for future applications of this framework. We then prove Lemma 5.2 and Theorem 5.3.

Lemma B.1: Let $A$ and $B$ be compact metric spaces. Let $f: A \times B+R$

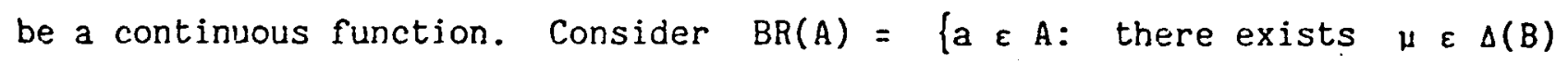
with $\left.a \varepsilon \underset{a \varepsilon A}{\arg \max } \int_{B} \hat{f}(a, b) d \mu(b)\right\} \quad(B R(A)$ is the set of actions in $A$, each of which is a best response against some mixed behavior on $B)$. Then $B R(A)$ is nonempty, compact and metric.

Proof: $B R(A) \neq \phi$ because given any $\mu \in \Delta(B), \int_{B} f(\cdot, b) d \mu(b)$ is continuous on the compact set $A$.

It is sufficient then to check that $B R(A)$ is closed since it is a subset of the compact and metric space A. Furthermore, it is enough to check sequentially. Let $a_{n} \varepsilon B R(A)$ converge to $\bar{a} \varepsilon A$. Then there exists $\mu_{n} \varepsilon \Delta(B)$ such that $a_{n}$ is a best response to $\mu_{n} \cdot \Delta(B)$ is sequentially compact so there is a subsequence $\left\{\mu_{n k}\right\}_{k=0}^{\infty} \rightarrow \bar{\mu} \varepsilon \Delta(B)$. Let us rename this subsequence $\mu_{n}$. By definition, $\forall n, \int_{B} f\left(a_{n}, b\right) d \mu_{n}(b) \geqq \int_{B} f(\hat{a}, b) d \mu_{n}(b)$ चa $\varepsilon A$. Define $f_{n}: B+R$ by $f_{n}(b)=f\left(a_{n}, b\right)$ and $\bar{f}: B+R$ by $\bar{f}(b)=f(\bar{a}, b)$. Then $f_{n}+\bar{f} \quad V b \in B$. Also, $f_{n}$ is dominated by the function $g(b) \equiv \max _{A \times B} F(\cdot, \cdot)$. Therefore by Hildenbrand (1974) Chapter 1, D.I.42, we have $\int_{B} f_{n} d \mu_{n}+\int_{B} \vec{f} d \mu$. Thus, taking the limits on both sides of the inequality above gives $\int_{B} f(\bar{a}, b) d \bar{\mu}(b) \geqq \int_{B} f(\hat{a}, b) d \bar{\mu}(b) \quad \bar{V} \hat{a} \varepsilon A \Rightarrow \bar{a} \varepsilon B R(A) . \quad$ Q.E.D. 
Lemma B.2: Let $A, B$ and $f$ be given as in Lemma B. 1. Let $v: B R(A) \rightarrow \Delta(B)$ be the following correspondence: $\forall$ a $\in B R(A), \quad u(a)=$ $\left\{v \in \Delta(B): a \varepsilon \underset{a \in A}{\arg \max } \int_{B} f(\hat{a}, b) d u(b)\right\}$. Then $v$ is upper semi-continuous.

Proof: By Hildenbrand (1974) chapter 1, B.III.Th.1, it is enough to check that $a_{n} \rightarrow a, u_{n} \in u\left(a_{n}\right), u_{n}+u \Rightarrow u \varepsilon v(a)$. But since $u_{n} \varepsilon v\left(a_{n}\right)$, we have as in Lemma B. 1:

$$
\int_{B} f\left(a_{n}, b\right) d u_{n}(b) \geqq \int_{B} f(\hat{a}, b) d u_{n}(b) \quad \forall \hat{a} \varepsilon A
$$

Therefore by arguments identical to Lemma B.1 we have $U$ E $U(a)$ Q.E.D.

Let $G$ be the graph of the correspondence of the above lemma:

$$
G=\{(a, v) \varepsilon B R(A) \times \Delta(B): \quad v \varepsilon v(a)\} .
$$

Lemma B.3 For $\mu_{C} \varepsilon \cdot \Delta(A)$, such that

Supp $\mu_{C}=C$ (where $C$ is an arbitrary closed subset of $B R(A)$ ) there is a $\mu \varepsilon \Delta(A \times \Delta(B))$ such that

(i) $\operatorname{marg}_{A} \mu=\mu_{C}$

(ii) Supp $\mu \subset G_{C}=\{(a, u) \in G, a \in C\}$.

Proof: $\forall D \subset \Delta(A \times \Delta(B))$, D Borel measurable, Define $\mu(D)=\mu_{C}\left(\operatorname{Proj}_{A}(D \cap G)\right)$.

This is possible because given $B R(A)$ is closed in $A$, one can view $G$ as a closed subset of $A \times \Delta(B)$, therefore $G$ is measurable. Hence $\mu$ is well defined and (i) and (ii) are verified easily.

Q.E.D.

Proposition B. 1: $\forall i, \ell, A_{i}^{\ell}$ is compact metric. 
Proof: Straightforward application of Lemma B.1 repeatedly. Q.E.D.

Proposition B.2: $\forall i, \ell, k_{i}^{\ell}$ is compact metric.

Proof: It is: sufficient to show that $k_{i}^{l}$ is closed since it is a subset of $S_{i}^{\infty}$ which is compact metric. We demonstrate this by induction. $F i x \quad i$ and consider $l=1$.

$k_{i}^{1}=\left\{s_{i}^{\infty} \in s_{i}^{\infty}: \forall j,\left(a_{j}, s_{j}^{\infty}\right) \in \operatorname{supp} \operatorname{marg}_{A_{j} \times S_{j}^{\infty}}\left[\phi_{i}\left(s_{i}^{\infty}\right)\right] \Rightarrow a_{j} \in \underset{a_{j} \in A_{j}}{\arg \max } V\left(\hat{a}_{j}, s_{j}^{\infty}\right)\right\}$ Again it is enough to check that $s_{i n}^{\infty} \rightarrow s_{i}^{\infty}$ and $s_{i n}^{\infty} \varepsilon K_{i}^{1} \Rightarrow s_{i}^{\infty} \varepsilon K_{i}^{1}$. But as $\phi_{i}$ is an homeomorphism, $\phi_{i}\left(s_{i n}^{\infty}\right)+\phi_{i}\left(s_{i}^{\infty}\right)$. This implies that $\operatorname{marg}_{A_{j} \times S_{j}^{\infty}}\left[\phi_{i}\left(s_{i}^{\infty}\right)\right]+\operatorname{marg}_{A_{j} \times S_{j}^{\infty}}\left[\phi_{i}\left(s_{i}^{\infty}\right)\right]$. Let $\left(a_{j}, s_{j}^{\infty}\right) \varepsilon \operatorname{supp} \operatorname{marg}_{A_{j} \times S_{j}^{\infty}}\left[\phi_{i}\left(s_{i}^{\infty}\right)\right]$ and let $B_{j}^{e}\left(a_{j}, s_{j}^{\infty}\right)$ be an open ball of radius $e>0$. around it in $A_{j} \times s_{j}^{\infty}$. By weak convergence: lim inf $\mu_{j}^{n}\left(B_{j}^{e}\left(a_{j}, s_{j}^{\infty}\right)\right) \geqq \mu_{j}\left(B_{j}^{e}\left(a_{j}, s_{j}^{\infty}\right)\right)>0$ where

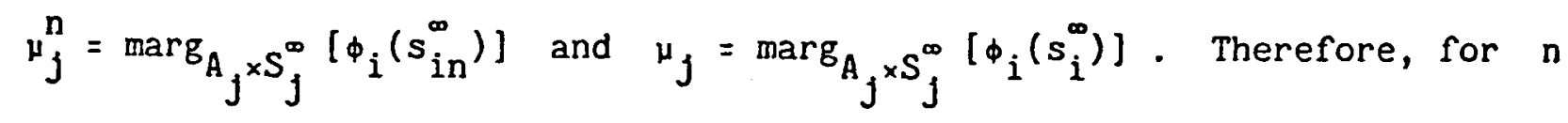
large enough, $\mu_{j}^{n}\left(B_{j}^{e}\left(a_{j}, s_{j}^{\infty}\right)\right)>0 \Rightarrow\left(a_{j}, s_{j}^{\infty}\right) \varepsilon$ supp $\mu_{j}^{n}$. But then $a_{j} \in \underset{a_{j} \in A_{j}}{\arg \max } V\left(a_{j}, s_{j}^{\infty}\right) \Rightarrow s_{i}^{\infty} \in k_{i}^{1}$. Let us assume the induction hypothesis that

$\psi_{i}$, and $\ell \geqq 1, K_{i}^{\ell}$ is closed. We shall show that $k_{i}^{\ell+1}$ is closed. Let $s_{i n}^{\infty} \varepsilon K_{i}^{\ell+1}$. This implies that $\forall j, \forall s_{j}^{\infty} \in \operatorname{supp} \operatorname{marg}_{S_{j}^{\infty}}^{\infty}\left[P_{i}\left(s_{i n}^{\infty}\right)\right]$ then $s_{j}^{\infty} \in k_{j}^{\ell}$. By the same argument as above, we have $s_{j}^{\infty} \varepsilon$ supp $\operatorname{marg}_{S_{j}^{\infty}}\left[\phi_{i}\left(s_{i}^{\infty}\right)\right] \Rightarrow s_{j}^{\infty} \varepsilon \operatorname{supp} \operatorname{marg}_{s_{j}^{\infty}}^{\infty}\left[\phi_{i}\left(s_{i n}^{\infty}\right)\right]$ for $n$ large enough (here we use the assumption that $k_{j}^{\ell}$ is closed). Hence $s_{j}^{\infty} \varepsilon k_{j}^{\ell}$. 
Moreover, since $k_{i}^{\ell}$ is closed, $s_{i}^{\infty} \varepsilon k_{i}^{\ell}$. So $s_{i}^{\infty} \varepsilon K_{i}^{\ell+1}$. Hence $k_{i}^{\ell+1}$ is closed.

Q.E.D.

We are now in a position to provide:

Proof of Lemma 5.2: We shall proceed by induction. For $\ell=1$, by the definition of $A_{i}^{2}$, if $a_{i} \varepsilon A_{i}^{2}$, there exists $\mu_{i}\left(a_{i}\right) \varepsilon \Delta\left(A_{-i}^{1}\right)$ such that $a_{i} \varepsilon \arg \max V\left(\hat{a}_{i}, \mu_{i}(a i)\right)$. Define $\bar{R}_{j}^{1}: A_{j}^{1}+\Delta\left(A_{-j} \times S_{-j}^{\infty}\right)$ by $\bar{R}_{j}\left(a_{j}\right)=$ $a_{i} \in A_{i}$

$\left\{\mu \varepsilon \Delta\left(A_{-j} \times S_{-j}^{\infty}\right): a_{j} \varepsilon \arg \max V\left(\hat{a}_{j}, \mu\right)\right\} \cdot \bar{R}_{j}^{-1}$ is clearly non-empty space since $a_{j} \varepsilon A_{j}$

by the definition of $A_{j}^{1}$, for $a_{j} \varepsilon A_{j}^{1}$, there exists $\mu_{j}\left(a_{j}\right)$ s.t.

$a_{j} \varepsilon \arg \max v\left(\hat{a}_{j}, \mu_{j}\left(a_{j}\right)\right)$. Then any $\mu \varepsilon \Delta\left(A_{-j} \times S_{-j}^{\infty}\right)$ whose marginal on $a_{. j} \varepsilon A_{j}$

$A_{j}$ is $\mu_{j}\left(a_{j}\right)$ is in $\bar{R}_{j}^{l}\left(a_{j}\right)$. Moreover, $\bar{R}_{j}$ is upper semi-continuous by Lemma B.2. Define $R_{j}^{1}: A_{j}^{1}+S_{j}^{\infty}$ by $R_{j}^{1}=\phi^{-1} \circ \bar{R}_{j}^{1}$. Since $\phi^{-1}$ is continuous, $R_{j}^{1}$ is upper semi-continuous. Let $G R_{j}^{1}$ be the graph of $R_{j}^{1}$. Then by a construction identical to that used in Lemma B.3, there is $\mu \varepsilon \Delta\left(A_{-i} \times S_{-i}^{\infty}\right)$ such that $\operatorname{marg}_{A_{-i}} \mu=j_{i}\left(a_{i}\right)$ and supp $\mu \subset \underset{j \neq i}{\mathbb{I}} \mathrm{GR}_{j}^{1}$. Now let $s_{i}^{\infty}=\phi^{-1}(\mu)$. By construction, $a_{i} \varepsilon \arg \max V\left(\hat{a}_{i}, s_{i}^{\infty}\right)$.

$$
\hat{a}_{i} \in A_{i}
$$

Moreover,

$\left(a_{j}, s_{j}^{\infty}\right) \in \operatorname{supp} \operatorname{marg} \underset{A_{j} \times S_{j}^{\infty}}{\phi_{i}}\left(s_{i}^{\infty}\right) \Rightarrow\left(a_{j}, s_{j}^{\infty}\right) \varepsilon G R_{j}^{1} \Rightarrow a_{j} \varepsilon \underset{a_{j} \in A_{j}}{\arg \max } V\left(\hat{a}_{j}, s_{j}^{\infty}\right)$.

Hence, $s_{j}^{\infty} \varepsilon K_{j}^{1}$. Now we shall assume that the induction hypothesis is true for every $\mathrm{J}$ and $\ell-1$. We need to show that it is true for $\ell$. 
For $a_{i} \in A_{i}^{l+1}$, there exists $\mu_{i}\left(a_{i}\right) \in \Delta\left(A_{-i}^{l}\right)$ s.t. $a_{i} \varepsilon \arg \max v\left(\hat{a}_{i}, \mu_{i}\left(a_{i}\right)\right)$. $a_{i} \in A_{i}$

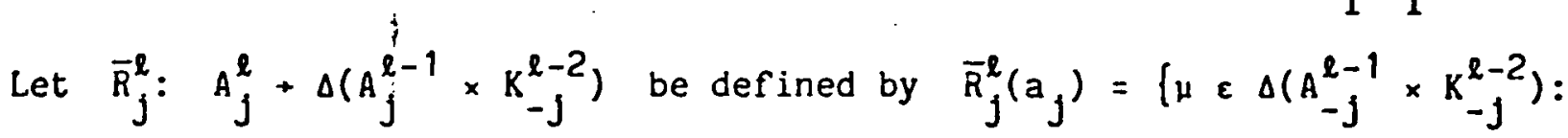

$\left.a_{j} \varepsilon \underset{a_{j} \in A}{\arg \max } V\left(\hat{a}_{j}, j^{j}\right)\right\}$

This is non-empty since by the induction hypothesis, there exists $s_{j}^{\infty} \varepsilon k_{j}^{\ell-1}$ such that $a_{i} \in \arg \max v\left(\hat{a}_{j}, s_{j}^{\infty}\right)$

$$
a_{j} \in A_{j}
$$

By Lemma 5.1, supp $\operatorname{marg}_{A_{-j}} \phi_{j}\left(s_{j}^{\infty}\right) \subset A_{-j}^{\ell-1}$. Moreover by the definition of $k_{j}^{\ell-1}$, $s_{k}^{\infty} \varepsilon \operatorname{supp} \operatorname{marg} s_{k}^{\infty}\left[\phi_{j}\left(s_{j}^{\infty}\right)\right] \Rightarrow s_{k}^{\infty} \varepsilon k_{k}^{l-2}$. So that $s_{j}^{\infty} \varepsilon \bar{R}_{j}^{l}\left(a_{j}\right)$. Moreover, by Lemma B.2, $\bar{R}_{j}^{l}$ is upper semi-continuous. Notice also that

$\mu \varepsilon \bar{R}_{j}^{\ell}\left(a_{j}\right) \Rightarrow \phi_{j}^{-1}(\mu) \in K_{j}^{\ell-1}$ by construction. Define $R_{j}^{\ell}: A_{j}^{l}+K_{j}^{\ell-1}$ by $R_{j}^{l}=\phi^{-1} \circ R_{j}^{l} . \quad R_{j}^{l}$ is upper semi-continuous.

Again by a construction identical to lemma B.3, there exists $\mu \varepsilon \Delta\left(A_{-i} \times S_{i}^{\infty}\right)$ such that $\operatorname{marg}_{A_{-i}} \mu=\mu\left(a_{i}\right)$ and $\operatorname{supp} \mu<\underset{j \neq i}{\mathbb{I}} \mathrm{GR}_{j}^{\ell}$. Let $s_{i}^{\infty}=\phi^{-1}(\mu)$. Then $s_{i}^{\infty}$ rationalizes $a_{i}$ by construction, $a_{i} \varepsilon \arg \max v\left(\hat{a}_{i}, s_{i}^{\infty}\right)$. Moreover,

$$
\text { - } \hat{a}_{i} \in A^{0}
$$

$\left(a_{j}, s_{j}^{\infty}\right) \varepsilon \operatorname{supp} \operatorname{marg} A_{j} \times s_{j}^{\infty} \phi_{i}\left(s_{i}^{\infty}\right) \Rightarrow\left(a_{j}, s_{j}^{\infty}\right) \varepsilon G R_{j}^{l}$, hence $s_{j}^{\infty} \varepsilon K_{j}^{l-1}$. So that $s_{i}^{\infty} \in k_{i}^{2}$

Proof of Theorem 5.3: Since $a_{i} \varepsilon \underset{\ell \geq 1}{n} A_{i}^{l}, \forall \ell, a_{i} \in A_{i}^{l+1}$. So by Lemma 5.2, there exists $s_{i \ell}^{\infty} \varepsilon K_{i}^{\ell}$ which rationalizes $a_{i}$. Observe that $s_{i \ell+k}^{\infty} \varepsilon K_{i}^{\ell}$ 
for all $k \geq 0$. Since $k_{i}^{\ell}$ is metric, we can find a convergent subsequence which converges toi $s_{i}^{\infty}(\ell) \varepsilon K_{i}^{\ell}$. Moreover, $s_{i}^{\infty}(\ell)$ rationalizes $a_{i}$ and it is the limit of beliefs which satisfy successively higher orders of rationality.

Let us show that $s_{i}^{\infty}(l) \varepsilon k_{i}^{\ell+\bar{k}} \forall \bar{k} \geq 0$. Let $\bar{k}$ be given. Then for $k \geq \bar{k}, \quad s_{i \ell+k}^{\infty} \varepsilon K_{i}^{\ell+\bar{k}}$. Therefore the subsequence has another subsequence which converges to a point in $k_{i}^{\ell+\bar{k}}$. However, since the orginal subsequence was convergent to $s_{i}^{\infty}(l)$, it must mean that $s_{i}^{\infty}(l) \in k_{i}^{\ell+\bar{k}} \forall \bar{k} \geq 0$. Hence $s_{i}^{\infty}(l)$ satisfies rationality is common knowledge and rationalizes $a_{i}$ in $A_{i}^{l+1}$. We can now take a subsequence of $s_{i}^{\infty}(\ell)$ which converges and the limit is in $\underset{\ell \geq 0}{n} K_{i}^{\ell}$ and which rationalizes $a_{i}$ in $\underset{\ell \geq 1}{n} A_{i}^{\ell} . \quad$ Q.E.D. 
(a partir de n: 50)

50. JOGOS DE INFOR.AAÇÃO INCOMPIETA: UMA INTRODUÇÃO - Sérgio Ribei ro da Costa Werlang - 1984 (esgotado)

51. A TEORIA MONETERIA MODERNA E O EQUILIBRIO GEPAL WALRASIANO COM UM NOMERO INFINITO DE BEISS - A. Araujo - 1984. (esgotado)

52. A INDETERHINAÇÃ.O DE MORGENSTERN - Antonio Maria da Silveira - 1984 (esgotado)

53. O PROBLEMA DE CREDIBILIDADE EM POLITICA ECONŌMICA - Rubens Pentia Cysne 1984 (esgotado)

54. UNA ANALISE ESTATISTICA DAS CAUSAS DA EMISSÃO DO CHEQUE SEM FUNDOS: FORHULAÇÄ́ DE UM PROJETO PILOTO - Fernando de Holanda Barbosa, Clovis de Faro e Aló́sio Pessoa de Araujo - 1984

55. POLTTICA MACROECONÖMICA NO BRASIL: 1964-66 - Rubens Penha Cysne - 1985 (esgotado)

56. EVOLUÇÃO DOS PLANGS BASICOS DE FINANCIAMENTO PARA RQUISIÇÃO DE CASA PROFRIA DO BANCO NACIONAL DE HABITAÇẼo: 1964-1984 - Clovis de Faro - 1985 (esgotado)

57. MOEDA INDEXADA - Rubens P. Cysne - 1985 (esgotado)

58. INFLACÃ̃O E SALÁRIO REAL: A EXPERIENCIA BRASILEIṘA - Raul José Ekerman 1985 (esgotado)

59. O ENFOQUE MONETARIO DO BALANÇO DE PAGAMENTOS: UM RETROSPECTO - Valdir Ramalho de Melo - 1985 (esgotado)

60. MOEDA E PREÇOS RELATIVOS: EVIDENCIA EMPIRICA - Antonio SaLazar P. Brandão 1985 (esgotado)

61. INTERPRETAÇĂO ECONOMICA, INFLAÇÃO E INDEXAÇÃO - Antonio Maria da Silveira 1985 (esgotado)

62. MACROECONOMIA - CAPITULO 1 - o SISTEMA MONETARIO - Mario Henrique Simonsen e Rubens Penha Cysne - 1985 (esgotado)

63. MACROECONOMIA - CAP TTULO II - O BALANÇO DE PAGANENTOS - Mario Henrique Simonsen e Rubens Penha Cysne - 1985 (esgotado)

64. MACROECONOHIA - CAPITULO 111 - AS CONTAS NACIONAIS - Mario Henrique Simonsen e Rubens Penha Cysne - 1985 (esgotado)

6.5. A DEMANDA POR DIVIDENDOS: UMA JUSTIFICATIVA TEORICA - TOMMY CHIN-CHIU TAN $E$ Sérgio Ribeiro da Costa Werlang - 1985 (esgotado)

66. BREVE RETROSPECTO DA ECONOMIA BRASILEIRA ENTRE 1979 e 1984 - Rubens Penha Cysne - 1985

6\%. CONTRATOS SALARIAIS JUSTAPOSTOS E POLITICA ANTI-INFLACIONARIA - Mario Henrique Simonsen - 1985 
68. INFLAÇÃO E POLITICAS DE RENDAS - Fernando de Holanda Barbosa e Clovis de Faro - 1985 (esgotado)

69. BRAZIL INTERNATIONAL TRADE AND ECONOMIC GROWTH - Mario Henrique Simonsen - 1986

70. CAPITALIZAÇÃo CONTINUA: APLICAÇÕES - Clovis de Faro - 1986 (esgotado)

71. A RATIONAL EXPECTATIONS PARADOX - Mario Henrique Simonsen - 1986 (esgotado)

72. A BUSINESS CYCLE STUDY FOR THE U.S. FORM 1889 TO 1982 - Carlos I van Sinionsen Leal - 1986

73. DINÁMICA MACROECONOMMICA - EXERCICIOS RESOLVIDOS E PROPOSTOS - Rubens Penha Cysne - 1986 (esgotado)

74. COMMON KNOWLEDGE AND GAíE THEORY - Sérgio Ribeiro da Costa Werlang - 1980

75. HYPERSTABILITY OF NASH EQUILIBRIA - Carlos I van Simonsen Leal - 1986

76. THE BROWN-VON NEUMANN D!FFERENTIAL EQUATION FOR BIMATRIX GAMES Carlos Ivan Simonsen leal - 1986 (esgotado)

77. EXISTENCE OF A SOLUTION TO THE PRINCIPAL'S PROBLEM - Carlos Ivan Simonsen Leal - 1986

78. FILOSOFIA E POLITICA ECONOMICA I: Variações sobre o Fenômeno, a Ciência e seus Cientistas - Antonio Maria da Silveira - 1986

79. O PREÇO DA TERRA NO BRASIL: VERIFICAÇÃO DE ALGUMAS HIPÚTESES - Antonio Salazar Pessoa Brandão - 1986

80. IETODOS MATEMATICOS DE ESTATISTICA E ECONOMETRIA: Capitulos 1 e 2 Carlos Ivan Simonsen Leal - 1986 - (esgotado)

81. BRAZII.IAN INOEXING AND INERTIAL INFLATION: EVIDENCE FROM TIME-VARYING ESTIMATES OF AN INFLATION TRANSFER FUNCTION

Fernando de Holanda Barbosa e Paul D. McNelis - 1986

82. CONSÓRCIO VERSUS CREDITO DIRETO EM UM REGIME DE MOEDA ESTÁVEL - Clovis de Faro $\therefore 1986$

83. NOTAS DE AULAS DE TEORIA ECONOMICA AVANÇADA I - Carlos Ivan Simonsenleal-1986

34. FILOSOfia e POLITICA ECONÔMICA II - Inflação e Indexação - Antonio Maria da Silveira - 1936 - (esgotado)

85. SIGNALLING AND ARBITRAGE - Vicente Madrigal e Tommy C. Tan - 1986

86. ASSESSORIA ECONOMICA PARA A ESTRATEGIA DE GOVERNOS ESTADUAIS: ELABORACÖLS SOBRE UHA ESTRUTURA ABERTA - Antonio Maria da Silveira - 1986 - (csirntalo)

87. THE CONSISTENCY OF WELFARE JUDGEMENTS WITU A REPRESENTATIVE, CONSUMER - Janes Dow e Sérgio Ribeiro da Costa Werlang 
88. INDEXAÇÃO E ATIVIDADE AGRICOLAS: CONSTRUÇÃO E JUSTIFICATIVA PARA A ADOÇÃO DE UM INDICE ESPECIFICO - Antonio Salazar P. Brandão e Clóvis de Faro - 1986

89. MACROECONOMIA COM RACIONAMENTO UM MODELO SIMPLIFICADO PARA ECONOMIA ABERTA - Rubens Penha Cysne, Carlos Ivan Simonsen Leal e Sérgio Ribeiro da Costa Werlang - 1986

90. RATIONAL EXPECTATIONS, INCOME POLICIES AND GAME THEORY - Mario Henrique Simonsen - 1986 - ESGOTADO

91. NOTAS SOBRE MODELOS DE GERAÇÕES SUPERPOSTAS 1: OS FUNDAMENTOS ECONÔMICOS - Antonio Salazar P. Brandão - 1986 - ESGOTADO

92. TOPICOS DE CONVEXIDADE E APLICAÇÕES Ā TEORIA ECONÔMICA - Renato Fragelli Cardoso - 1986

93. A TEORIA DO PREÇO DA TERRA: UMA RESENHA

- Sérgio Ribeiro da Costa Werlang - 1987

94. INFLAÇÃO, INDEXAÇÃO E ORÇAMENTO DO GOVERNO - Fernando de Holanda Barbosa $-1987$

95. UMA RESENHA DAS TEORIAS DE INFLAÇÃO

- Maria Silvia Bastos Marques - 1987

96. SOLUÇõES ANALITICAS PARA A TAXA INTERNA DE RETORNO - Clovis de Faro - 1987

97. NEGOTIATION STRATEGIES IN INTERNATIONAL ORGANISATIONS:

A GAME - THEORETIC VIEWPOINT - Sérgio Ribeiro da Costa Werlang - 1987

98. O INSUCESSO DO PLANO CRUZADO: A EVIDÊNCIA EMPIRICA DA INFLAÇÃO 100\% INERCIAL PARA O BRASIL - Fernando de Holanda Barbosa e Pedro L. Valls Pereira - 1987 
92. UN TEMA REVISITADO: A RESPOSTA DA PRODUÇÃO AGRICOLA AOS PRELOS NO BRASIL - Fernando de Holanda Barbosa e Fernando da Silva Santiago - 1987

100. JUROS, PIEÇOS E DIVIDA POBLICA VOLURE I: ASPECTOS TEORICOS -

- Marco Antonio C. Martins e Clovis de Faro - 1987

101. JUROS, PREÇOS E DIVIDA PJBLICA VOLURE II: A ECONOMIA BRASTLEIRA (1971/1985)

- Antonio Salazar P. Brandão, Clóvis de Faro e Marco Antonio C. Martins - 1987

102. MACROECONOMIA KALECKIANA - Rubens Penha Cysne - 1987

103. O PRÊTIO DO DOLAR NO NERCADO PARALELO, O SUBFATURAMENTO DE EXPORTAÇÕ:S E 0 SUPERFATURAMENTO DE IMPORTAÇÕES - Fernando de Holanda Barbosa - Rubens Penha Cysne e Marcos Costa Holanda - 1987

104. BRAZILIAN EXPERIENCE WITH EXTERNAL DEBT AND PROSPECTS FOR CROWTH Fernando de Holanda Barbosa and Manuel Sanchez de La Cal - 1987

105. KEYNES NA SEDIÇĀO DA ESCOLHA POBLICA

- Antonio Maria da Silveira - 1987

106. O TEOREMA DE FROBENIUS-PERRON - Carlos Ivan Simonsen Lea1 - 1987

107. Populaçño bRASIleirh - Jessē Nontello - 1987

108. MACROECONOMIA - CAPITULO VI: "DEMANDA POR MOEDA E A CURVA LM" - Mario Henrique Simonsen e Rubens Penha Cysne - 1987

109. MACROECONOMIA - CAPITULO VII: "DEMANDA AGREGADA E A CURVA IS" - Mario Henrique Simonsen e Rubens Penha Cysne - 1987

110. MACROECONOMIA - MODELOS DE EQUILIBRIO AGREGATIVO A CURTO PRAZO Mario Henrique Simonsen e Rubens Penha Cysne - 1987 
111. THE BAYESIAN FOUNDATIONS OF SOLUTION CONCEPTS OF GAMES - Sérgio Ribeiro da Costa Werlang e Tommy Chin - Chiu Tan - 1987 